\title{
Animal Models for Target Diseases in Gene Therapy - using DNA and siRNA Delivery Strategies
}

\author{
Ian S. Blagbrough ${ }^{1,2}$ and Chiara Zara ${ }^{1}$
}

Received May 9, 2008; accepted May 29, 2008; published online October 8, 2008

\begin{abstract}
Nanoparticles, including lipopolyamines leading to lipoplexes, liposomes, and polyplexes are targeted drug carrier systems in the current search for a successful delivery system for polynucleic acids. This review is focused on the impact of gene and siRNA delivery for studies of efficacy, pharmacodynamics, and pharmacokinetics within the setting of the wide variety of in vivo animal models now used. This critical appraisal of the recent literature sets out the different models that are currently being investigated to bridge from studies in cell lines through towards clinical reality. Whilst many scientists will be familiar with rodent (murine, fecine, cricetine, and musteline) models, few probably think of fish as a clinically relevant animal model, but zebrafish, madake, and rainbow trout are all being used. Larger animal models include rabbit, cat, dog, and cow. Pig is used both for the prevention of foot-and-mouth disease and human diseases, sheep is a model for corneal transplantation, and the horse naturally develops arthritis. Non-human primate models (macaque, common marmoset, owl monkey) are used for preclinical gene vector safety and efficacy trials to bridge the gap prior to clinical studies. We aim for the safe development of clinically effective delivery systems for DNA and RNAi technologies.
\end{abstract}

KEY WORDS: efficacy; gene delivery; pharmacodynamics; pharmacokinetics; RNAi.

\section{INTRODUCTION}

Gene therapy consists of the modification of gene expression for therapeutic gain; it is dependent on an understanding of basic biological principles. In many, if not most, gene therapy studies, a "corrected" gene is inserted into the genome to replace an "abnormal" disease-causing gene (Fig. 1). A carrier (a vector) must be used to deliver the therapeutic gene to the patient's target cells. The most common vectors are viruses that have been genetically altered to carry normal human DNA. All viruses attack their hosts and introduce their genetic material into the host cell as part of their replication cycle, and therefore they are used as vehicles to carry "good" genes into a human cell. Numerous problems exist that lessen the likelihood of success for gene therapy using viral vectors: many undesired effects (the vectors are often toxic or immunogenic), hard to ensure the virus will infect the target cells in the body, and the inserted gene must not disrupt any vital genes already in the genome. However, companies persist with this method of gene introduction.

There are also non-viral methods for gene therapy (1-4). Although low levels of transfection and gene expression

\footnotetext{
${ }^{1}$ Department of Pharmacy and Pharmacology, University of Bath, Bath BA2 7AY, UK.

${ }^{2}$ To whom correspondence should be addressed. (e-mail: prsisb@ bath.ac.uk)
}

mean that non-viral vectors are still less efficient, they present certain advantages over viral methods with simple large scale production and low host immunogenicity being just two. Recent advances in non-viral cationic lipid vector technology have yielded molecules and techniques with transfection efficiencies similar to those achieved with viruses. In modern non-viral methods, plasmid DNA is coated with lipids in an organized structure, as a lipoplex or polyplex (if from cationic polymers, Fig. 2) (1-4), or small interfering RNA (siRNA) to signal the cell to cleave specific sequences in the mRNA transcript of the faulty gene, disrupting its translation and therefore silencing expression of the gene $(4,5)$.

In theory, the transformation of either somatic cells or cells of the germ-line is possible. All gene therapy to date on humans has been directed at somatic cells, whereas germ-line engineering in humans (rightly) remains controversial. Over the last two decades, gene transfer experiments for the treatment of inherited or acquired diseases have been performed. Gene therapy has moved from preclinical to clinical studies for many diseases ranging from single gene disorders such as cystic fibrosis and Duchenne muscular dystrophy, to more complex diseases such as cancer and cardiovascular disorders (6). For a better understanding of the structure and function of human genes, and to develop new strategies in order to combat diseases, we should compare the human genome with genomes of other organisms, identifying regions of similarity and difference.

Comparative genome studies found that the DNA sequence similarities with humans are about $70-90 \%$ 


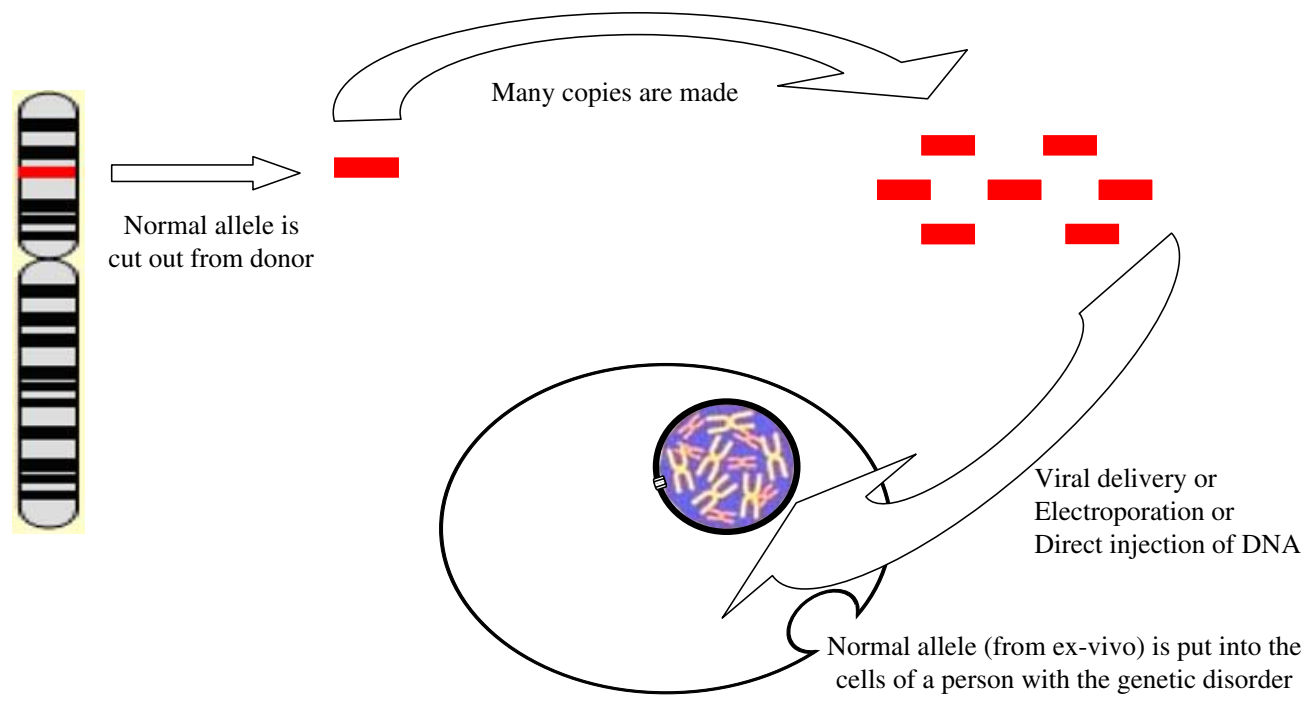

Fig. 1. The basic process of ex-vivo gene therapy.

$(\sim 85 \%)$ the same in mice (http://www.ornl.gov/sci/techresour ces/human_genome/faq/compgen.shtml), but with a lot of key variations (e.g. some mouse and human gene products are almost identical, while others are nearly unrecognizable as close relatives), $75 \%$ in dogs (http://www.home.earthlink.net/ blindworld2/index.htm), $71 \%$ in pigs (7). Cat and primate share $73 \%$ of their genomes (8). Among the 768 known genes of cattle, $638(83 \%)$ could be identified as identical to human genes (http://www.scienceblog.com/community). All rabbit chromosome paints, except the Y paint, hybridized to human chromosomes and all human chromosome paints, except the Y paint, hybridized to rabbit chromosomes (9). Chimpanzee DNA sequence is $98.8 \%$ identical to ours (http://www. genome.gov). Fruit fly genome and our human genome have $60 \%$ of genes in common (http://nes.bbc.co.uk). Also, we share half our genes with a banana (http://www.wasdarwin right.com/homology.htm)!

Animal models of human diseases are important in the development and assessment of gene therapy. This is particularly evident in the evaluation of gene therapy

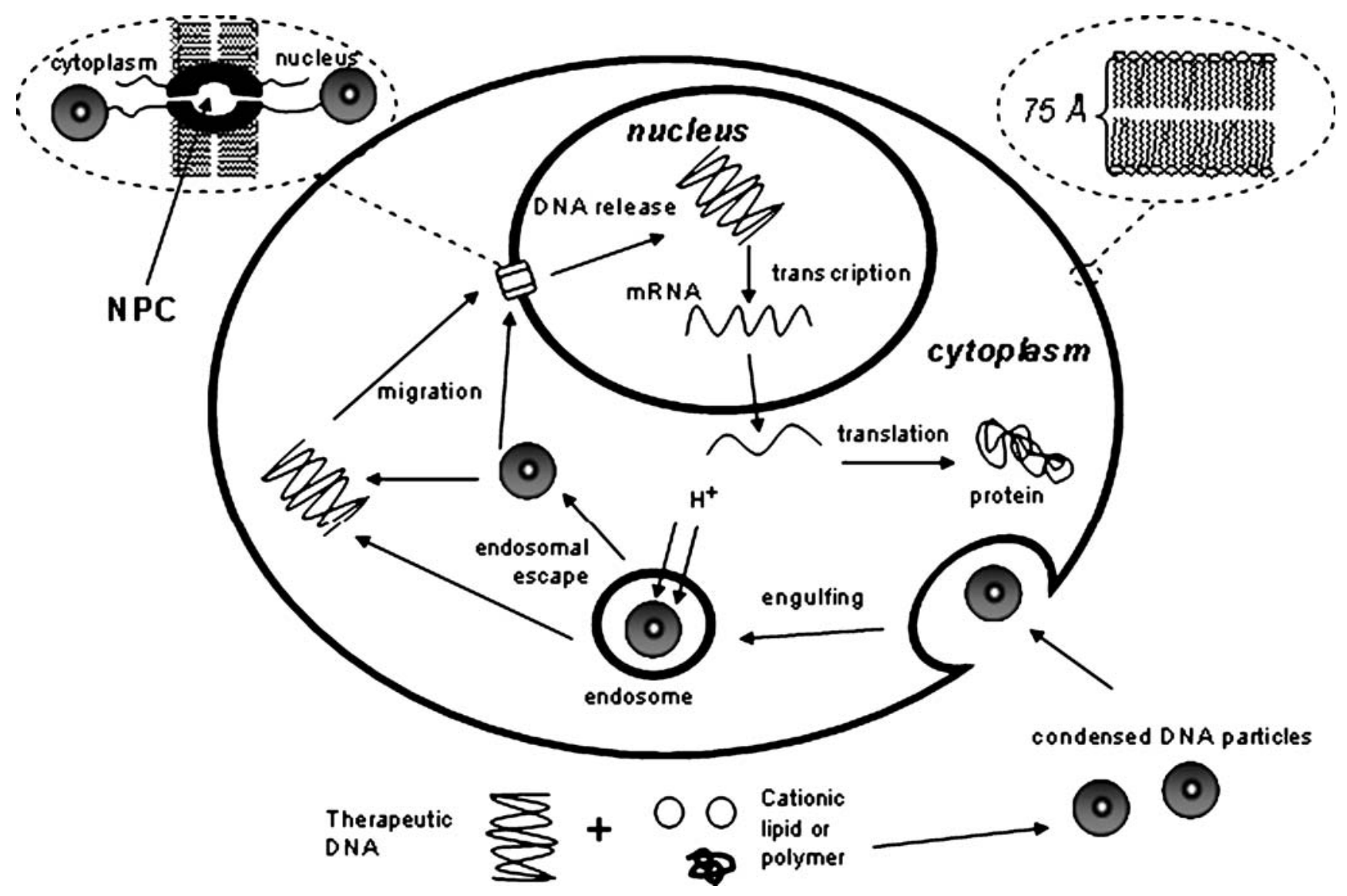

Fig. 2. Non-viral gene therapy. 
protocols for clinical trials as gene transfer studies with statistically and rationally meaningful outcomes need to be evaluated in models that closely resemble human diseases. Animal models clearly are an important step in the preclinical evaluation of human-directed gene transfer protocols which are not possible in humans for ethical and lack of volunteer reasons $(10,11)$.

RNA interference (RNAi) is already a recognized functional genomics research tool for mammalian gene knock-down studies, target discovery, and validation. It shows great diagnostic and therapeutic potential (Fig. 3). Of course, there could be huge commercial potential for gene therapy products. For these reasons biotechnology and pharmaceutical companies are investing in the development of gene therapy and RNAi technologies. It could reduce the time needed for target validation and drug development, accelerating the drug discovery process. RNAi-based screens provide new opportunities for the discovery and validation of novel therapeutic targets in several disease areas e.g. cancer and infectious diseases. A significant effect of an oligonucleotide on the disease phenotype indicates that the target in question plays an important role in the disease state. Potent RNAi compounds can provide important tools for in vivo validation and can be administered in animal models of disease in order to determine if inhibition of expression results in a corresponding in vivo change in the disease phenotype (12). An RNAi knockdown model can be produced in a fraction of the time and cost required for previous antisense "knockout mouse" technologies, and so (in remarkably short order) these have been largely replaced by RNAi-based systems. The precise (selective) mechanism of siRNA action reduces the potential for side-effects (few off-target effects). Delivery and intracellular stability of siRNA agents are the major hurdles (3-5,13-15).

Translation of emerging technologies into commercially viable therapeutics involves a consideration of competing technologies, safety, efficacy, and regulatory issues (12). RNAi therapeutics are being studied for the treatment of: age-related macular degeneration (AMD), cancer, infections, influenza, cardiovascular, CNS and metabolic disorders. More specifically, these targets include: hypercholesterolemia, respiratory diseases, metabolic diseases, hepatitis $\mathrm{C}$ virus (HCV) in the liver, liver cancers, and the p53 gene is targeted for the treatment of renal failure. There is hope for the treatment of neurodegenerative diseases: Parkinson's disease and progressive multifocal leukoencephalopathy (PML) which is caused by infection of the CNS with "JC virus" and can occur in immune-suppressed patients, including those receiving immunomodulatory therapies. Targeting the Huntington's disease gene will be delivered by Medtronic's implantable infusion pump. So, will the technology be free of delivery problems and safety issues? What accurate animal models exist to help answer these important questions? We review ten different animal models used to answer key questions about efficacy, pharmacodynamic $(16,17)$ or pharmacokinetic $(18,19)$ modelling prior to clinical trials.

\section{ANIMAL MODELS}

Gene therapy like any other administration of a new drug has to be tested in animal models before clinical application in humans. The early animal models for gene therapy were focussed upon simulated inherited (genetic) disorders, judged to be appropriate candidates for early human trials and based heavily upon molecular medicine in animals genetically engineered to reflect the disease state (20-22). Transgenic animals are used to model different human diseases: infection, neurodegeneration, apoptosis, arteriosclerosis, ageing, cancer, xenografts, etc. (20-22). One goal is to use these models to assess the potential efficacy of a genetic intervention by evaluating its impact on meaningful surrogate or clinical endpoints.

Clearly, most of the gene transfer experiments have been performed in mice. Large animal models, such as pigs or horses, are almost exclusively used to study treatment of induced diseases, cardiovascular disease and arthritis, respectively $(10,11)$. Sheep and non-human primates are used for the development of gene transfer techniques, gene marking studies, and assessment of safety, but despite the existence of genetic diseases in these species, they have not yet been used for treatment trials. However, aspects of the human population that are impossible to simulate in animal models are the tremendous environmental and genetic diversity. This will be particularly important in the context of immune responses to

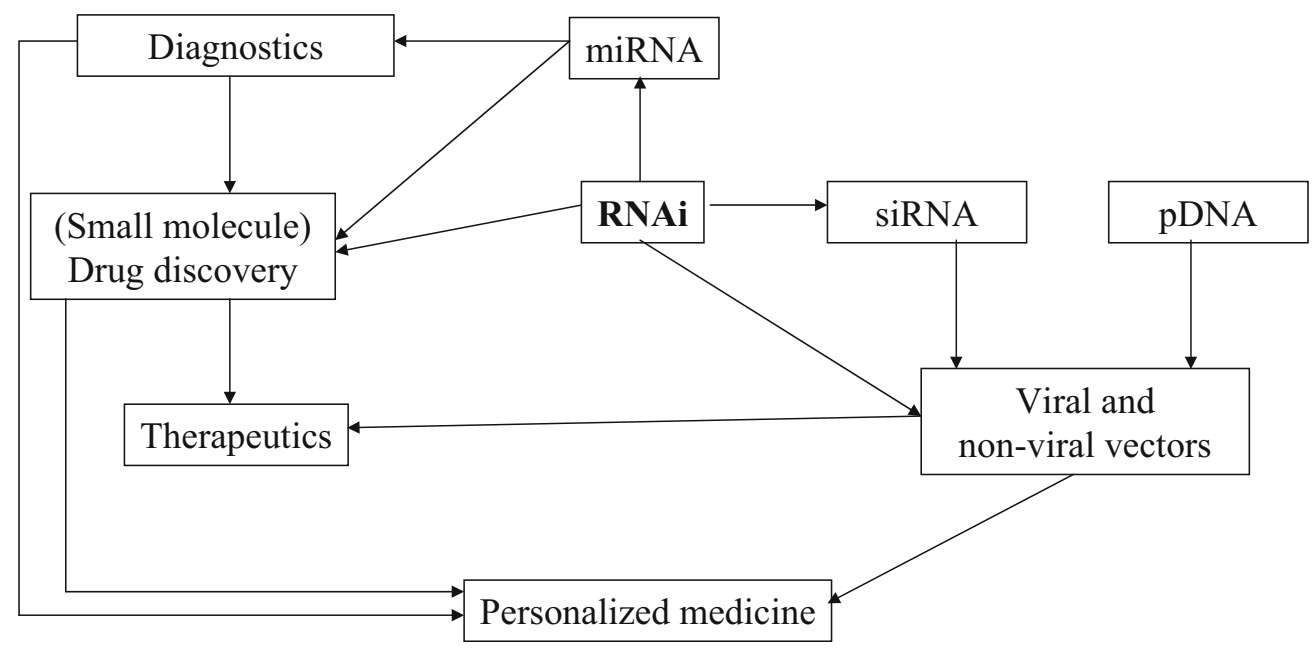

Fig. 3. Genomics research tools. 
gene replacement therapy where several factors may profoundly contribute to outcome, such as nature of mutations in the disease gene, major histocompatibility genotype, and previous exposure of the recipient to the delivery vehicle in the context of naturally acquired infection.

Epstein Barr Virus (EBV), is associated with an increasing number of lymphoid and epithelial malignancies. Among the genes expressed by EBV during latency, LMP1 plays a key role for growth transformation and immortalization of B lymphocytes. In elegant studies, from the Dept. of Public Health Sciences, University "La Sapienza", Rome, Galletti et al. (23), have shown that antisense oligonucleotides (ONs) directed to LMP1 mRNA, effectively suppressed LMP1 gene expression and substantially reduced proliferation of the infected cells (using a marmoset cell line). As the use of antisense phosphodiester oligonucleotides as therapeutic agents is limited by inefficient cellular uptake and intracellular transport to the target mRNA, they therefore tested the ability of three cationic carriers internalized by different pathways, to increase the delivery of anti-LMP1-ON to their site of action in EBVinfected B lymphocytes. Liposomes, dendrimers or transferrin-polylysine-conjugated $\mathrm{ON}$ were internalized by the cells at an extent several-fold higher than that of the naked oligomers. However, only the delivery system exploiting the transferring-receptor mediated pathway was able to vectorize biologically active antisense LMP1-ON.

These cell line studies typify a lot of current pharmaceutical research in non-viral gene therapy. Our own work on DNA condensation and cell-line transfection is similarly poised to make the transition in to animal models for target diseases in gene therapy $(1,4,24-30)$.

\section{FISH MODELS}

Few probably think of fish (piscine models) as a clinically relevant animal model. However, zebrafish (Danio rerio) (3133) and medaka (Oryzias latipes) (34-36) are used as initial models of gene delivery and even as animal models of human disease e.g. hepatic diseases and cancer (37). Rainbow trout (Oncorhynchus mykiss) models (38) are also being used. Zebrafish is a good model for a better understanding of congenital diseases, such as Achromatopsia, and campomelic dysplasia or defects in neural crest development that are a significant cause of human disease. One of these is Waardenburg's Syndrome, a neurocristopathy in which individuals have dominant pigmentation defects. Loss of specific cone types causes partial colour blindness, whereas general loss of cone function causes total colour blindness or macular degeneration (33). Another is related to deafness. Medaka is a fish model for studying the organogenesis process, haemoglobin-bilirubin metabolism, and the function of Toll1 receptor (34-36). In rainbow trout, adjuvant effects on the early response to a viral hemorrhagic septicemia virus (VHSV) immunization has been investigated. DNA vaccines against fish rhabdovirus (VHSV) using expression plasmids coding for the viral glycoprotein (pMCV1.4-G) co-administered with cloned interleukin 8 (pIL8+), and specifically the route of delivery and the efficient use of adjuvants are under investigation (37).

\section{RODENT MODELS}

The importance of rodent (murine, fecine, cricetine, and musteline) models for DNA and siRNA delivery strategies is self-evident from their number. Murine (mouse and rat) models depend on the assumption that their biological processes very closely resemble those in humans. They are also inexpensive to keep, their generation time is short, and they have large litters. However, murine models may fail to mirror faithfully the human diseases and longitudinal studies are not possible because of their short lifespan. Thus, large animal models of human genetic diseases complement murine studies because they have a longer lifespan, are more similar in size to a neonate or child, their background genetic heterogeneity is similar to that of humans, and they are genetically more closely related to humans than mice $(10,11)$.

Mice are still used to study many different diseases e.g. cancer, haemophilia, neurological diseases, SCID, Duchenne muscular dystrophy and many others. These models provide us with differentiated tissues, which are not often available from human sources. Furthermore, they allow for testing the effects of genetic manipulation and experimental therapeutics on physiology and pathology. In Duchenne muscular dystrophy, the mutations in the dystrophin gene occur in the region encoding the spectrin-like central rod domain. Splicing around mutations can generate a shortened, but in-frame transcript, thereby permitting translation of a partially functional dystrophin protein. This was tested in vivo in the dystrophic mouse, carrying a mutation in exon 23 of the dystrophin gene. The treated mice showed persistent production of dystrophin at normal levels in large numbers of muscle fibres with functional improvement of the treated muscle (38).

The most common lethal genetic disease in the Caucasian population is cystic fibrosis $(\mathrm{CF})$. $\mathrm{CF}$ is a monogenic disease whose phenotype variability is attributed to genetic variation in the "modifier" genes. Several research groups have interrupted or incorporated specific mutations into the CF transmembrane conductance regulator gene (CFTR) $(39,40)$. Lethal gastrointestinal manifestations of the disease were prevented by introducing into the germ line of a $\mathrm{CF}$ mouse a transgene encoding human CFTR expressed from a gut-specific promoter $(39,40)$.

Several studies have demonstrated efficient in vivo delivery of siRNA (13-15). The first direct delivery of siRNA in vivo was carried out using the "hydrodynamic" technique of administering naked siRNA in a large volume of a physiological solution, under high pressure, into the tail vein of mice. In order to evaluate the efficacy of this delivery method, mice were co-injected with plasmids expressing the luciferase gene as a reporter along with synthetically prepared siRNA targeted to the luciferase mRNA (Fig. 4) (41).

Most gene transfer experiments are performed in mice, an early model for the switch from cell lines to in vivo (42). Using hydrodynamic delivery (tail vein) to mouse, there is recent evidence that siRNA is better than shRNA (encoded by plasmid DNA) for in vivo knockdown (43). Liver fibrosis, induced by $\mathrm{CCl}_{4}$ or bile duct ligation, was ameliorated by adenoviral gene transfer of (matrix metalloproteinase) MMP- 


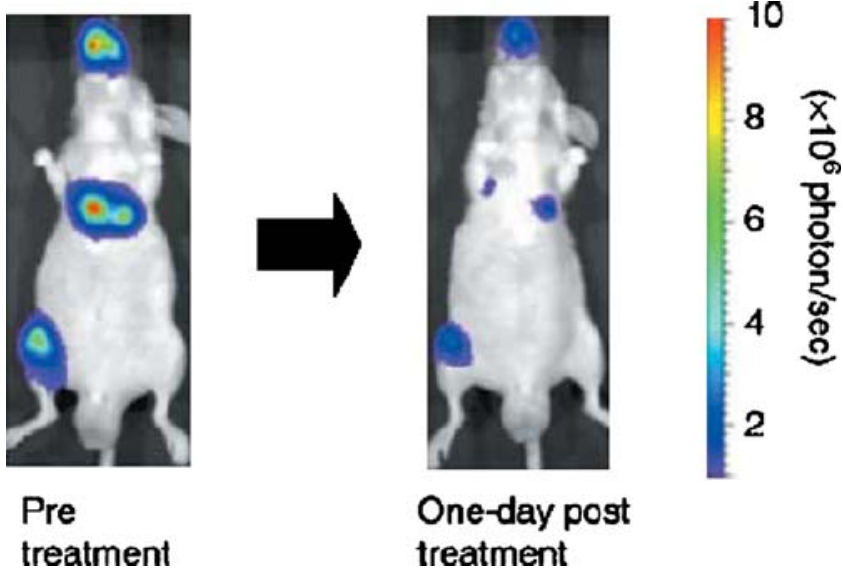

Fig. 4. Monitoring luciferase inhibition in vivo using bioluminescent imaging. The images of nude mice injected with $3 \times 10^{6}$ PC-3M-luc-C6 cells into the left ventricle of the heart. Four weeks after tumour injection, each animal was administered with luciferase GL3 siRNA complexed with $0.05 \%$ atelocollagen. On the next day, the bioluminescent signals of most of the metastatic sites were inhibited by $80-90 \%$ in the whole body (41). Reprinted with permission (41).

8, human neutrophil collagenase, in rat models (44). Earlier, adenoviral gene transfer with human urokinase-type plasminogen activator (UPA) also reversed experimental rat liver fibrosis inducing collagenase expression (45). So, gene delivery of interstitial collagenases is promising for the treatment of advanced cirrhosis in humans. However, persistent overexpression of interstitial collagenases in the liver possibly digests normal architectures in addition to pathologically deposited ECM. Therefore, precisely controlled delivery of active interstitial MMPs may be necessary for developing a clinical treatment (46).

With regard to treating genetic blindness, an animal model of Leber congenital amaurosis (LCA), the $\mathrm{Lrat}^{-1-}$ mouse, has the clinical features of this human disease. Intraocular injected rAAV-delivered Lrat gene therapy and oral pharmacological treatment with novel 9-cis-retinyl acetate and 9-cis-retinyl succinate, which are easier to synthesize and more stable than the 11-cis-isomers they replaced, successfully restored electroretinographic responses to $\sim 50 \%$ of wild-type levels ( $p<0.05$ versus wild-type and knockout controls), and pupillary light responses of $\mathrm{Lrat}^{-/-}$mice also increased $\sim 2.5 \mathrm{log}$ units (47).

The therapeutic utility of cytochrome P450-based enzyme pro-drug therapy is well established by preclinical studies and in initial clinical trials. The underlying premise of this gene therapy is that intratumoural $\mathrm{P} 450$ expression leads to in situ activation of anticancer $\mathrm{P} 450$ pro-drugs, such as cyclophosphamide (CPA), with intratumoural accumulation of its activated 4-OH metabolite and favourable pharmacokinetics as shown in mice bearing 9L gliosarcomas (a subcutaneous solid tumour an in vivo model for inoperable pancreatic carcinoma) expressing P450 2B11, but not P450 2B6. Therefore, there is an advantage in gene therapy strategies that combine low $K_{\mathrm{m}} \mathrm{P} 450$ pro-drug activation enzymes with slow, localized release of $\mathrm{P} 450$ pro-drug substrates. This recent work of Waxman and colleagues at Boston University followed their report in 2000 of a pharmacokinetic study of $\mathrm{P} 450$ reductase and CPA activation in a rat cancer gene therapy model $(48,49)$.

To establish non-viral gene delivery systems for intravenous administration, complexes of pDNA and PLL and PEI block copolymer were tested in in vivo turnover studies. The polyion complex micelles have self-assembling core-shell structures, yielding spherical nano-particles which were administered i.v. into male balb/c mice as part of a pharmacokinetics study in cardiovascular research. Though having no targeting ligands, these micelles efficiently transfected HepG2 cells. When the micelles were injected via the supramesenteric vein, expression of the gene was observed only in the liver and this was sustained for 3 days. It was concluded that this gene delivery system is intrinsically efficient (50).

Interleukin-2 (IL-2) immunotherapy is a potent treatment for cancer, but dangerous side-effects stand in the way of its progress. A pharmacokinetics and safety evaluation, using mice and cynomolgus monkeys, was performed with a lipoplex encoding human IL-2 by Norman, Parker, and colleagues at Vical in support of phase I human cancer therapy clinical trials $(51,52)$.

Kissel and co-workers in the Department of Pharmaceutics and Biopharmacy (53), Marburg, have long being studying PEI in order to make DNA polyplexes which efficiently show DNA condensation, measured in the ethidium bromide fluorescence quenching assay which we optimized (54). They have compared transfection efficiency results in various different cell lines with pharmacokinetics and biodistribution in mice, where approximately half of the injected dose accumulated in the liver. They demonstrated that low molecular weight PEI is better (less toxic and higher transfection efficiency) than PEI of high molecular weight (53).

RNAi can knock down oncogenes in cancer, including brain cancer, but the therapeutic potential of RNAi will not be realised until the rate-limiting step of delivery is solved. The view in 2004 was that "development of RNA-based therapeutics is not practical, due to the instability of RNA in vivo. However, plasmid DNA can be engineered to express short hairpin RNA (shRNA), similar to endogenous microRNAs." A new i.v. non-viral RNAi-based gene therapy, with a new gene-targeting technology, encapsulates the pDNA inside receptor-specific pegylated immunoliposomes (PILs). The feasibility of this RNAi approach was evaluated by showing it was possible to achieve a $90 \%$ knockdown of brain tumour-specific gene expression with a single intravenous injection in adult mice and rats with intracranial human brain cancer. The survival of these mice was extended by nearly $90 \%$ with weekly intravenous injections of PILs carrying pDNA expressing a shRNA directed against the human epidermal growth factor receptor. So, RNAi-based gene therapy can be coupled with gene therapy that replaces mutated tumour suppressor genes to build a polygenic approach to the gene therapy of cancer (55).

Adenoviruses (Ad) are robust gene delivery vectors in vivo, but are limited by their propensity to provoke strong innate and adaptive responses. PEG modification (with SPAPEG) of adenovirus can protect the vectors from pre-existing and adaptive immune responses by reducing protein-protein interactions and interactions with immune cells. Note that 
while increasing PEGylation of Ad vectors ablated in vitro transduction, it surprisingly had no negative effect on the level or distribution of in vivo gene delivery, possibly via heparin sulfate and integrin interactions. So, PEGylation can reduce innate immune responses without reducing transduction in vivo. Non-specific vector uptake by macrophages and Kupffer cells may be critically involved in the initial activation of innate immune responses $(56,57)$.

Early studies (1999) used direct injection for Admediated gene delivery in guinea pig (fecine) models (58). Ad-mediated delivery of RNAi has also recently afforded new anti-foot-and-mouth data in both guinea pig and pig. In comparative studies, male and female guinea pigs (250 to $300 \mathrm{~g}$ ) and large white swine (2- to 3-months-old, 40 to $50 \mathrm{~kg}$ ) were used to perform the viral challenges (59).

Gerbil and hamster (cricetine) models are also being used. Ad-mediated gene transfer of fibroblast growth factor-2 increases BrdU-positive cells after forebrain ischemia in gerbils (60) and Ad-mediated overexpression of a gene prevented hearing loss and progressive inner hair cell loss after transient cochlear ischemia in gerbils (61). rAAV types 2 and 5 showed distinct patterns of gene transfer to gerbil hippocampus (62), and rAAV-transduced vascular endothelial cells express the thrombomodulin transgene under the regulation of enhanced plasminogen activator inhibitor-1 promoter in Mongolian gerbils (63).

When type 1 protein phosphatase (PP1) is overactivated in the failing heart, there is a depression of cardiac function. In vivo PP1 inhibition by myocardial gene transfer of inhibitor-2 (INH-2), an endogenous PP1 inhibitor, alleviates heart failure (HF) progression in the cardiomyopathic hamster, a well-established HF model (64). AAV-mediated INH-2 gene delivery improved fractional shortening of the left ventricle accompanied by reduced chamber size at 1 week. AAV-mediated INH-2 gene delivery significantly extended the survival time for 3 months. These results provide a potential new treatment for $\mathrm{HF}$ without activating protein kinase A signalling in cardiomyocytes (64). The limb girdle muscular dystrophies (LGMD) are a genetically and phenotypically heterogeneous group of degenerative neuromuscular diseases. A subset of the genetically recessive forms of LGMD are caused by mutations in the four muscle sarcoglycan genes (alpha, beta, gamma, and delta). The coding sequences of all known sarcoglycan genes are smaller than $2 \mathrm{~kb}$, and thus can be readily packaged in rAAV-vectors for efficient delivery in a hamster model (Bio 14.6) after a single intramuscular injection. These results support the feasibility of rAAV-vector mediated delivery to treat LGMD by direct in vivo gene transfer (65).

In early studies (1994), ferret (musteline) models were used to show protection against influenza challenge in DNA vaccination against haemagglutinin with a gene gun for delivery of DNA-coated gold particles (66). More recently, Engelhardt and co-workers reported the comparative biology of rAAV transduction in ferret, pig, and human airway epithelial cells as well as improving the related animal models (67).

\section{RABBIT MODELS}

Familial hypercholesterolemia (FH) is an inherited disorder in humans caused by a deficiency of low density lipoprotein receptors (LDLR). Rabbit (lapine) models (Watanabe Heritable Hyperlipidemic) were used as a model for $\mathrm{FH}$ in order to develop an approach for liver-directed gene therapy based on transplantation of autologous hepatocytes that were genetically corrected ex vivo with recombinant retroviruses. Rabbits transplanted with LDLR-transduced autologous hepatocytes demonstrated a $30-50 \%$ decrease in total serum cholesterol that persisted for the duration of the experiment. Recombinant-derived LDLR RNA was harvested from these tissues with no diminution for up to 6.5 months after transplantation (68).

Rabbits are also used in the study of heart diseases. Using a percutaneous catheter-based approach and selective intracoronary artery delivery in adult (New Zealand) rabbits, various procedures were tested to optimize adenovirusmediated gene transfer efficiency, including pharmacological pre-treatment to increase vessel permeability, transient interruption of coronary flow, high-pressure delivery, and coronary venous sinus occlusion (69). Other studies were aimed at constructing a recombinant plasmid pcDNA3.1-VEGF165, to observe the effect of vascular endothelial growth factor 165 (VEGF165) gene therapy on bone defects in New Zealand white rabbits (Oryctolagus cuniculus) (70). The plasmid was injected into the injured site in one of the forelegs with bone defect as the experiment group. Physiological saline solution was injected into the opposite foreleg as the control group. At $1,2,4,6,8$, and 12 weeks after the operation, X-rays were taken to observe the repair and healing of the bone defects (Fig. 5). The VEGF165 mRNA was expressed at low level at week 2 , reached the peak at week 4 and then decreased a normal level after 6 weeks. At 12 weeks, bone healing and new bone were observed (70).
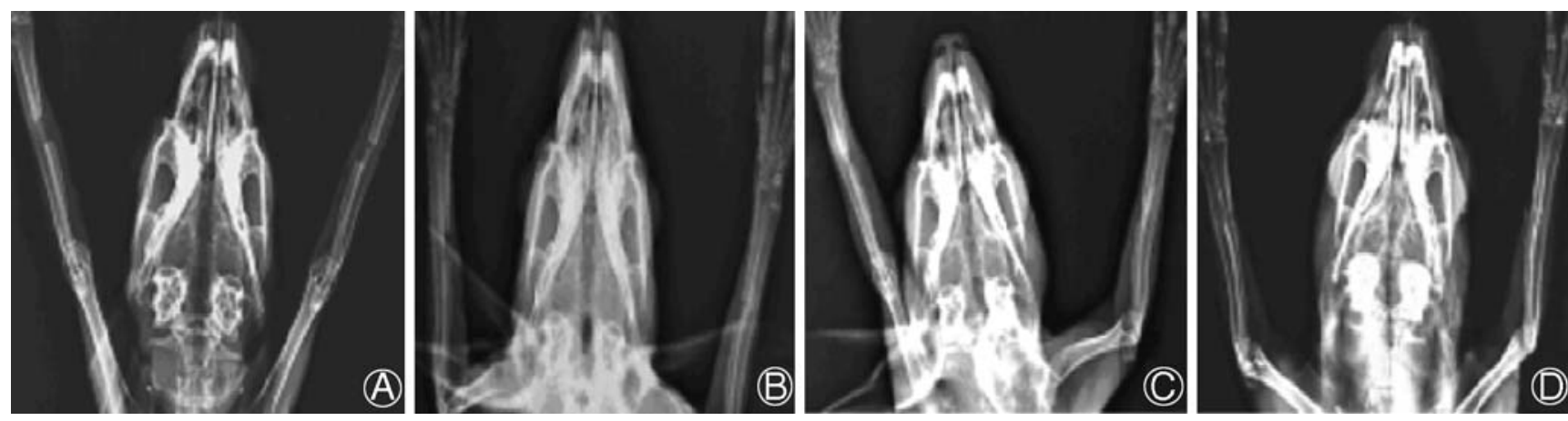

Fig. 5. X-ray of rabbit bone defects (70). Reprinted with permission of Chinese Medical Journal. 
Heme oxygenase-1 (HO-1) is a sensitive and reliable indicator of cellular oxidative stress. There are beneficial therapeutic applications of human $\mathrm{HO}$ gene transfer and gene therapy in a variety of clinical circumstances. The HO gene must be delivered in a safe vector, adenoviral, retroviral or leptosome based vectors are currently being used in clinical trials. With the exception of $\mathrm{HO}$ gene delivery to either ocular or cardiovascular tissue via catheter-based delivery systems, HO delivery must be site and organ specific. This has been achieved in rabbit ocular tissues, rat liver, kidney and vasculature, and spontaneously hypertensive rat (SHR) kidney (71).

\section{FELINE MODELS}

Cats are of particular interest for neurological disorders and their brains have been well characterized both functionally and physiologically. The anatomy of the cat brain is similar to that of a human. Lysosomal storage diseases are good candidates for CNS gene therapy, because active enzyme from genetically corrected cells can be secreted and taken up by surrounding diseased cells, and only small amounts of enzyme $(<5 \%$ of normal) are required to reverse storage lesions (72-74). Gene therapy was evaluated in brains of cats affected with $\alpha$-mannosidosis (AMD), a lysosomal storage disease caused by a deficiency of lysosomal $\alpha$ mannosidase (LAMAN) activity via the AAV1-fMANB vector (72). The disease in the cat is caused by a 4 bp deletion in the feline $\alpha$-mannosidase gene ( $\mathrm{f} M A N B)$ and is characterized by clinical signs, neuropathology, and biochemical abnormalities similar to those seen in human patients (75).

Magnetic resonance imaging (MRI) was performed on anesthetized cats (76-78). Treated cats showed the signal intensity of the cerebral white matter to be reduced (Fig. 6) (72). However, an improvement in cellular storage even at large distances from the transduction sites was seen. Perhaps due to diffusion of small quantities of LANAM from the injection site in distant brain regions or an alternate method of enzyme distribution, such as axonal transport or circulation through the cerebrospinal fluid (79-82). This study shows that somatic gene transfer to the CNS can deliver functioning enzyme directly to deficient brain cells without the high morbidity and mortality rates associated with bone marrow transplantation $(83,84)$.

\section{CANINE MODELS}

Over $50 \%$ of genetic diseases present in the dog are true orthologues of human diseases caused by mutation in the same genes. In addition to the obvious longevity and similarity in size to a small child, many parts of the canine immune system are similar to those of the human (85).

Mucopolysaccharidosis VII (MPS VII, Sly syndrome, $\beta$ glucuronidase deficiency) is an inherited lysosomal storage disorder caused by deficiency of $\beta$-glucuronidase activity, required for the catabolism of glycosaminoglycans whose accumulation in CV cells leads to cardiac disorders and also to CNS diseases. Haskins, Wolfe, and their co-workers, at the University of Pennsylvania, are making major contributions in this research area (86-91). The first animal model of MPS
VII was described in German Shepherd dogs. The cDNA sequences are known and the mutation has been identified. Some experiments tested intravenous retroviral (RV) vectors in neonatal dogs at days 2-3 of life (86). There was a significant improvement in the growth of treated dogs, and the skeletal disease was treated in their limbs (86). At 7 weeks of age the percent of normal enzyme activity in peripheral white blood cells containing vector sequence was very low compared to the neonatally treated dogs, which may help explain the benefit of the earlier treatment (87-91).

Hemophilia A and B have also been studied in dogs. They are $\mathrm{x}$-linked inherited bleeding disorders caused by a deficiency of the blood clotting factor in response to bleedings crises. The canine models of haemophilia are useful for developing and evaluating gene therapies because the canine proteins are very well characterized, the genes have been cloned, and cDNAs are available (92,93). Although vectorassociated toxicity (Fig. 7) remains an obstacle, a single injection of HDV led to long-term transgene expression and vector persistence in two FVIII-deficient animals with conversion of their severe phenotype to a moderate one (94).

The overall biological behaviour of malignant melanoma is very similar in dogs and in humans. Therefore, the dog is an ideal model for developing a therapy against these cancers. In a trial for canine oral melanoma, liposomes conjugated to Fas-ligand DNA were injected directly into the tumours to induce apoptosis (95). Tumour regression of $12-58 \%$ was observed in three of five treated dogs. No local or systemic adverse effects were observed over the course of the observation period (95-99) (Fig. 8).

Complete and reliable infiltration of the entire prostate is important to improve the efficacy of intraprostatic gene therapy, as well as drug delivery. The optimal injection scheme and feasibility of magnetic resonance imaging (MRI) was evaluated in an orthotopic canine model. MRI using gadolinium-diethylenetriamine pentaacetic acid is an excellent modality to evaluate the effective volume distribution of injectate in an in vivo orthotopic prostate model (100).

Leber congenital amaurosis (LCA), a heterogeneous early-onset retinal dystrophy, accounts for $\sim 15 \%$ of inherited congenital blindness. One cause of LCA is loss of the enzyme lecithin/retinol acyl transferase (LRAT), which is required for regeneration of the visual photopigment in the retina. LCA and early-onset severe retinal dystrophy (EOSRD) are genetically heterogeneous, (retinal pigment epithelium) RPE65 gene defects. LCA causes near total blindness in infancy. A naturally occurring animal model, the RPE65 $5^{-1-}$ dog, suffers from early and severe visual impairment similar to that seen in human LCA. After gene therapy to correct this RPE65 genetic defect, the dogs were able to walk through a maze, demonstrating improved vision. So, visual function was restored in this animal model of childhood blindness with rAAV delivery of wild-type RPE65 (AAV$R P E 65)$ (101). Of all the diseases with a genetic component, many scientists will be concerned about going blind. Can this be cured? Outstanding work, by Ali, Bainbridge, Moore, and colleagues at Moorfields Eye Hospital and in the Division of Inherited Eye Disease, UCL, is making real progress here (102). This is possibly the most clinically advanced topic covered in this review. The first gene therapy eye trial in humans with early onset retinal dystrophies as a result of 
Normal

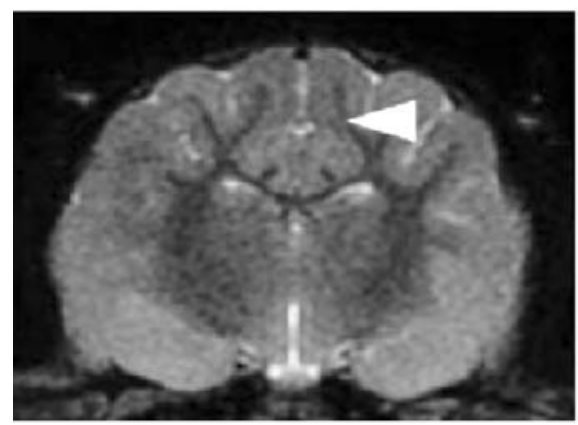

AMD

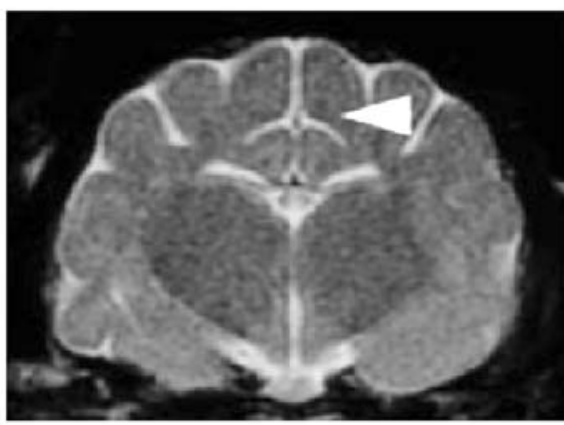

Treated

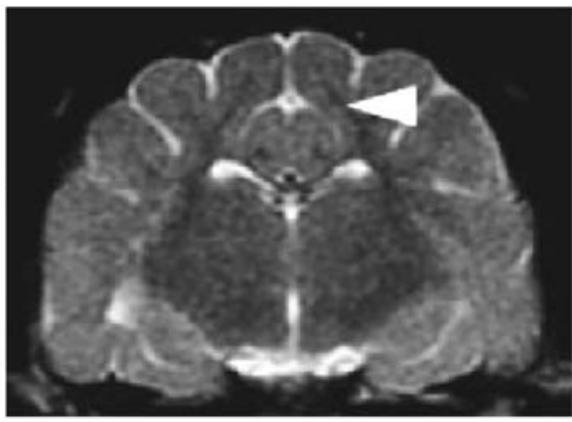

Brain region

\begin{abstract}
Normal $^{\wedge}$ (mean +i- SD)
\end{abstract}

$(n=3)$
$\mathrm{AMD}^{\wedge}$

(mean +/-SD)

$(n=3)$
Treated

(mean +/-SD)

$(\mathrm{n}=3)$

\begin{tabular}{cc}
\multicolumn{2}{c}{ P values } \\
\hline $\begin{array}{c}\text { Treated } \\
\text { versus } \\
\text { Normal }\end{array}$ & $\begin{array}{c}\text { Treated } \\
\text { versus } \\
\text { AMD }\end{array}$ \\
\hline 0.121 & $0.020^{*}$ \\
0.071 & $0.020^{*}$ \\
0.437 & $0.020^{*}$ \\
$0.019^{*}$ & $0.019 *$ \\
$0.020^{*}$ & 0.300
\end{tabular}

Corona radiata

Intemal capsule

Corpus callosum

Centrum semiovale

Cerebellar white

\section{$33.8+1-1.0$}

$33.2+/-0.7$

$32.1+1-0.9$

$33.4+1-0.4$

$35.4+/-0.7$
$30.4+/-0.6$

$30.4+1-0.3$

$27.1+/-0.4$

$29.4+1-1.2$

$30.8+1-1.5$

$32.5+/-0.3$

$32.2+/-0.8$

$31.5+/-1.0$

$32.1+/-0.8$

$31.7+1-2.2$

$\mathrm{s}<<0.05$

AValues for normal and AMD cats reported in Vite et al., 2001.

Fig. 6. Normalization of magnetic resonance imaging in adeno-associated virus serotype 1 vector-feline $\alpha$-mannosidase gene (AAV1-fMANB)treated cats. Transverse images of the cerebrum at the level of the thalamus in 16-week-old cats are shown (72). Copyright (2005) American Neurological Association; reprinted with permission of John Wiley \& Sons, Inc.

mutations in RPE65 has now started, and the successful results of the first three adult patients were presented this month; there are plans to enrol eight more patients this year (103). If this is successful, treatment of other genetic disorders such as LRAT deficiency will follow. The work in humans will eventually make it into a refereed paper, but this week (28.04.08) it was front-page stories in three major UK newspapers, "Steven Howarth, 18, from Bolton, recovered his sight enough to walk home at night". True peer review.

\section{BOVINE MODELS}

Calves weigh about $30-35 \mathrm{~kg}$ at birth, similar to the weight of a child, making them a good model to address scaling-up issues for therapies designed for older children. They are used as models of urea cycle defects like citrullinemia, a primary cause of hyperammonemia in the pediatric population and are associated with very high neurologic morbidity (Figs. 9 and 10) and mortality. Citrullinemia is
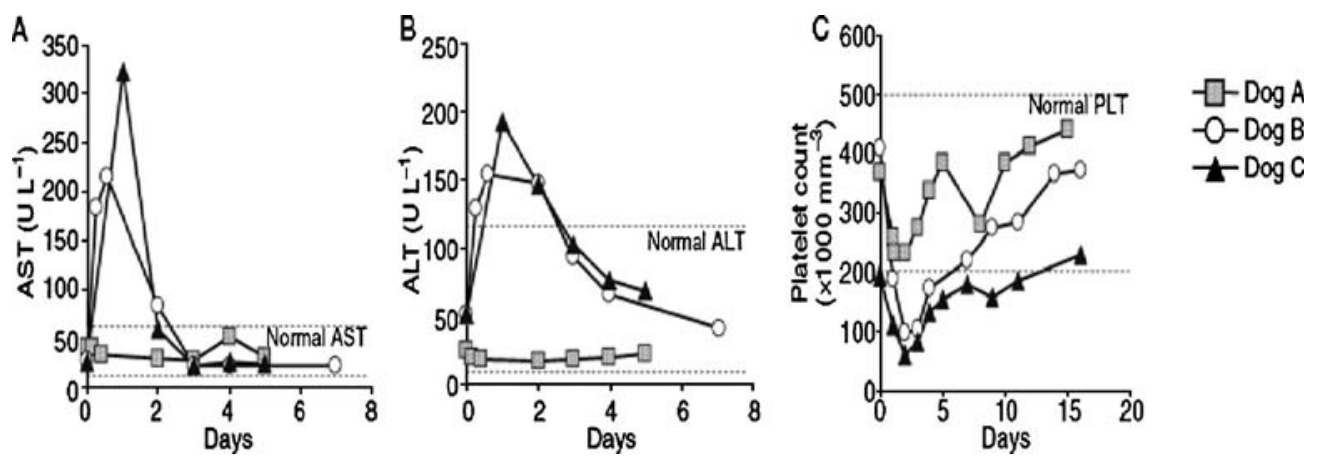

Fig. 7. Toxicity profiles in two hemophilic treated dogs. $\mathbf{A}$ aspartate aminotransferase and $\mathbf{B}$ alanine aminotransferase analyses of three dogs receiving either $1 \cdot 10^{12} \mathrm{vp} \mathrm{kg}^{-1}(\operatorname{dog} \mathrm{A})$ or $3 \cdot 10^{12} \mathrm{vp} \mathrm{kg}^{-1}(\operatorname{dogs} \mathrm{B}$ and C) HDV on day zero. C Platelet levels were measured for each dog throughout vector administration (94). Reprinted with permission (94). 

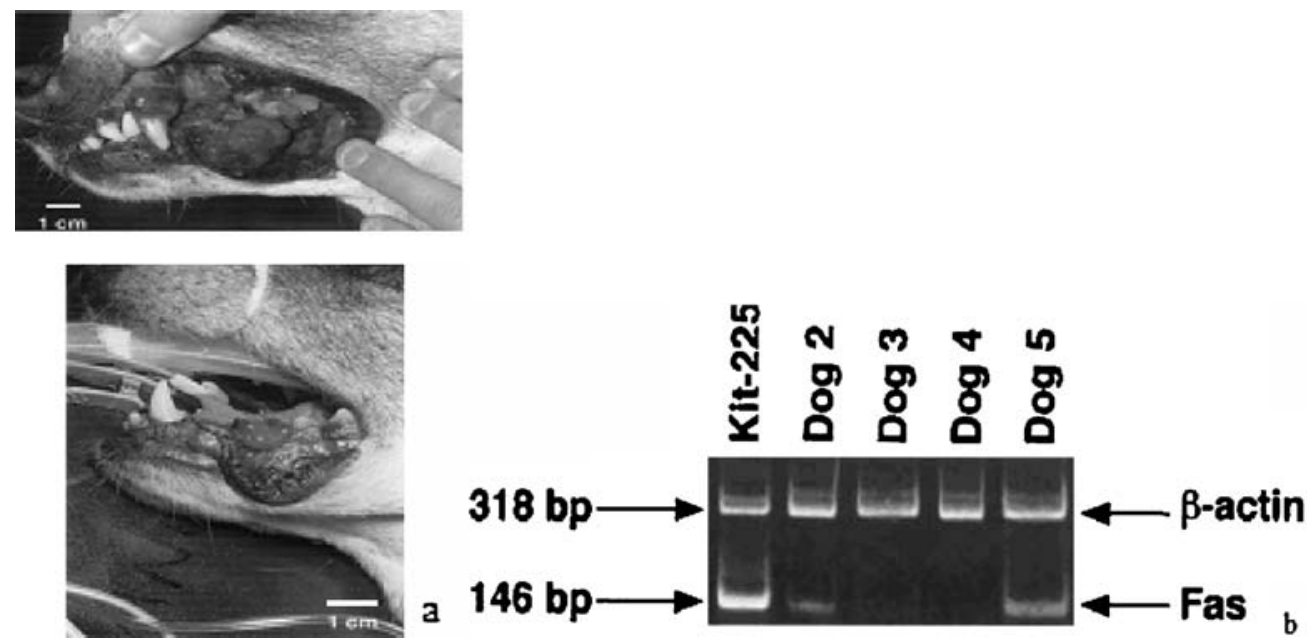

Fig. 8. a Effect of FasL gene therapy in a dog with oral melanoma. b Fas mRNA expression in tumours from dogs treated with FasL gene. Fas expression was examined by RT-PCR. The expression of $\beta$-actin was used as a loading control for the reactions and to ensure integrity of the RNA (95). Reprinted by permission from Macmillan Publishers Ltd: Cancer Gene Therapy (95); copyright (2003).

caused by a nonsense mutation ( $\mathrm{C}$ to $\mathrm{T}$ transition) in the gene coding for arginosuccinate synthetase in cattle (104). Although many of the clinical signs can be controlled by dietary restriction of protein, additional illness can easily result in hyperammonemia. For these studies of urea cycle defects two neonatal calves received an E1a-deleted adenovirus containing the human arginosuccinate synthetase cDNA intravenously. A week after administration of the adenovirus, both calves had elevated serum aspartate-amino-transferase concentrations whilst all other liver parameters remained normal at all time points (105).

\section{PIG MODELS}

Gene therapy could be a good antiarrhythmic strategy. Arrhythmia is an abnormal heartbeat of any type: too fast,

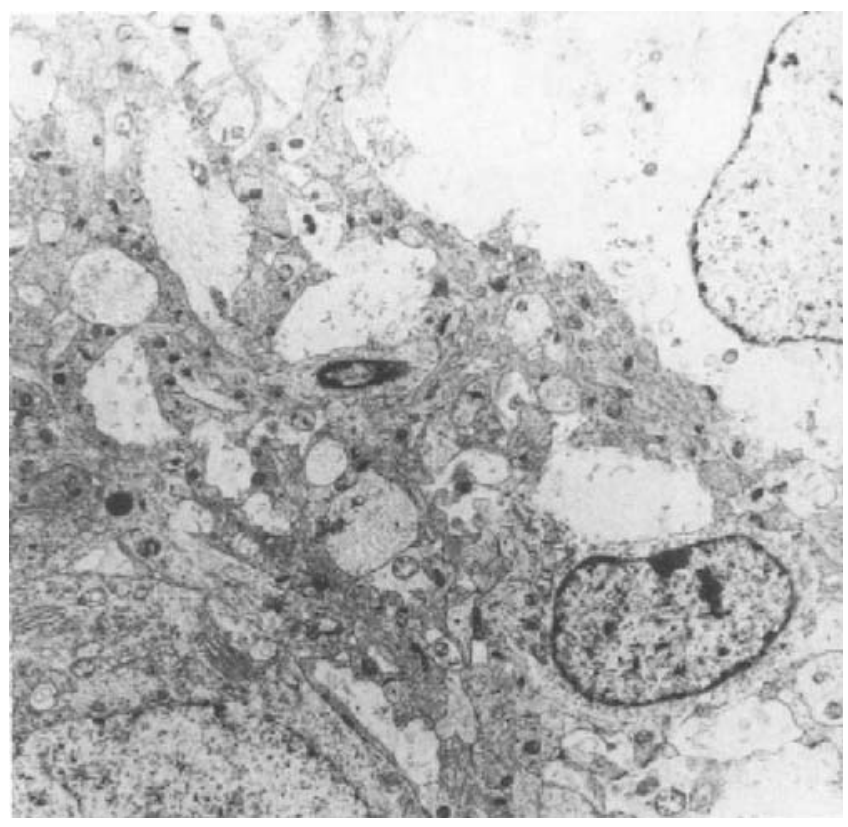

Fig. 9. Electron micrograph of the grey matter of the cerebral cortex of a citrullinemia-affect calf demonstrating edema of the cytoplasm of astroglial cells and their process (104). Reprinted from Harper et al. (104). too slow or just irregular. The heart can handle a few minutes of accelerated heartbeat, but repeated episodes can cause heart failure when the heart is simply too weak to pump blood properly, and this can lead to dizziness, collapse or death (106). A genetic modification of the atrioventricular node was investigated in an intracoronary perfusion model of heart arrhythmias in pigs for gene therapy. Using this method, porcine hearts were infected with Adßgal (rAd expressing Escherichia coli $\beta$-gal) or with $\mathrm{AdG}_{\mathrm{i}}$. (Ad encoding the $\mathrm{G} \alpha_{\mathrm{i} 2}$ subunit).

The hypothesis was that an excess of $\mathrm{G} \alpha_{\mathrm{i}}$ would mimic the effects of $\beta$-adrenergic antagonists, in effect creating a localized $\beta$-blockade. $\mathrm{G} \alpha_{\mathrm{i}}$ overexpression suppressed baseline atrioventricular conduction and slowed the heart rate during atrial fibrillation without producing complete heart block. In contrast, expression of the reporter gene $\beta$-galactosidase had no electrophysiological effects. One week after treatment the

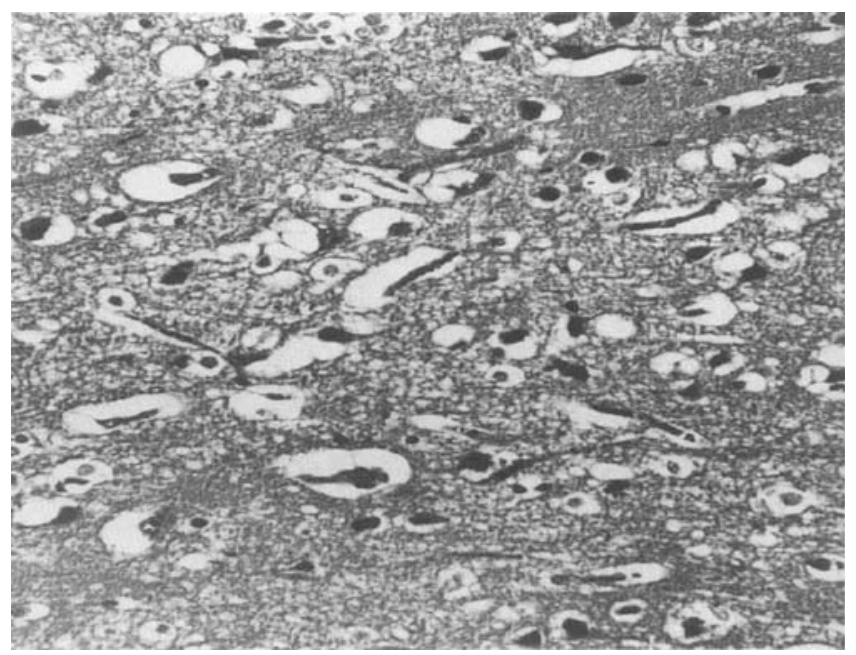

Fig. 10. Light micrograph of the grey matter of the cerebral cortex of citrullinemia-affected calf that demonstrates spongy change with expansion of perivascular spaces, and astroglial cell processes (104). Reprinted from Harper et al. (104). 
animals were killed and the organs were removed for histological evaluation (Fig. 11) (107,108).

Differences between rodent and human airway cell biology have made it difficult to translate recombinant adeno-associated virus (rAAV)-mediated gene therapies to the lung for cystic fibrosis (CF). As new ferret and pig models for CF become available from Engelhardt and co-workers (67), knowledge about host cell/vector interactions in these species will become increasingly important for testing potential gene therapies. $N$-Linked sialic acid receptors were required for rAAV1 and rAAV5 transduction of human and mouse airway epithelia, but not ferret or pig airway epithelia. Hence, although the airway tropisms of rAAV serotypes 1, 2, and 5 are conserved better among ferret, pig, and human as compared to mouse, viral receptors/co-receptors appear to maintain considerable species diversity (67).

Pigs are used not only in medicines research and development (59), but also for a new plasmid-mediated approach to supplement pig somatotropin production as reported by workers at ADViSYS in Texas (109). Admediated gene transfer of hyperpolarization-activated, cyclic nucleotide-gated cation channels (HCN4) creates a genetic pacemaker in pigs with complete atrioventricular block, searching for a cure by site-specific gene therapy for experimental cardiac bradyarrhythmia (110). Hydrodynamic gene delivery is an attractive option for non-viral liver gene therapy, but this approach requires evaluation of efficacy, safety, and clinically applicable techniques in large animal models. Fabre et al. evaluated retrograde delivery of DNA to the whole liver via the isolated segment of inferior vena cava (IVC) draining the hepatic veins, using pigs (18-20 kg) that were given pGL3 via two programmable syringe pumps in parallel with interspecies comparison in rats. The hydrodynamic procedure generated intrahepatic vascular pressures of
101-126 mmHg, which is approximately four times higher than in rodents, but levels of gene delivery were approximately 200-fold lower. This is a clinically acceptable approach to liver gene therapy. However, it is less effective in pigs than in rodents, possibly because of larger liver size or a less compliant connective tissue framework (111).

A cornerstone for an efficient cardiac gene therapy is the need for a vector system, which enables selective and longterm expression of the gene of interest. In rodent animal models, AAV vectors like AAV-6 have been shown efficiently to transduce cardiomyocytes. However, since significant species-dependent differences in transduction characteristics exist, large animal models are of imminent need for preclinical evaluations. Raake and co-workers compared gene transfer efficiencies of AAV-6 and heparin binding site-deleted AAV-2 vectors in a pig model by pressureregulated retroinfusion of the anterior interventricular cardiac vein, which has been previously shown to deliver genes efficiently to the myocardium $\left(3.5 \times 10^{10}\right.$ viral genomes per animal). All vectors had a luciferase reporter gene under cytomegalovirus (CMV)-enhanced $1.5 \mathrm{~kb}$ rat myosin light chain promoter (CMV-MLC2v) control. There was substantial increased reporter gene expression in the targeted distal left anterior descending (LAD) territory. Retroinfusion of AAV-2 vectors showed lower transgene expression which could be increased with coadministration of recombinant human VEGF. Significant transgene expression was not detected in other organs than the heart, although vector genomes were detected also in the lung and liver. Thus, they showed efficient long-term myocardial reporter gene expression in the targeted LAD area of the porcine heart (112).

Genetic modification of cells and animals is an invaluable tool for biotechnology and biomedicine. Workers in the

a
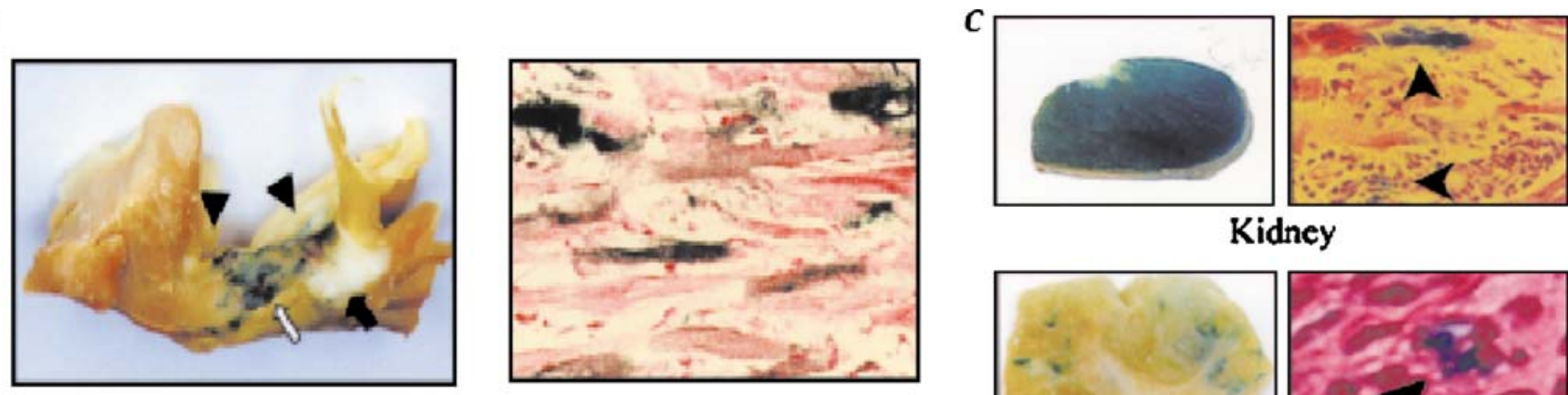

Kidney

$b$
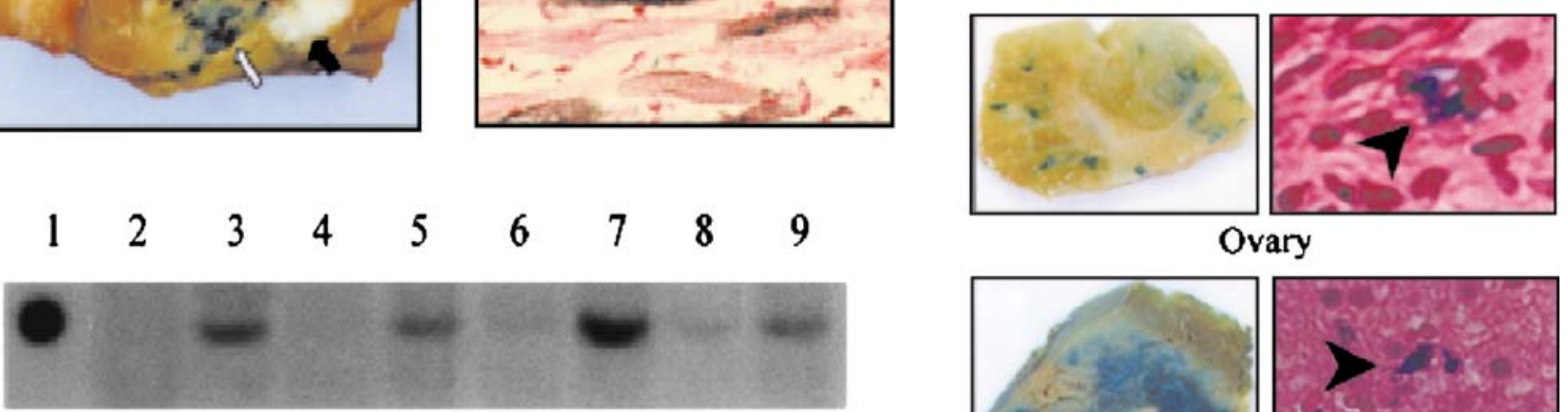

Ovary

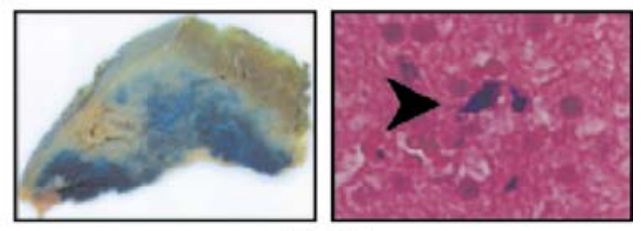

Liver

Fig. 11. Measurement of gene transfer efficacy. a X-gal staining of a transverse section through the AV groove. Cells expressing $\beta$-gal are stained blue. b Western blot of AV nodal tissue demonstrates $G \alpha_{\mathrm{i} 2}$ overexpression in the $\mathrm{AdG}_{\mathrm{i}}$ infected animals. c Gross and microscopic pathology after exposure of liver, kidney and ovary to X-gal solution (107). Reprinted by permission from Macmillan Publishers Ltd: Nature Medicine (107), copyright (2000). 
Department of Surgical Sciences, University of Milano, recently reported their results on genetically modified pig foetuses, delivered to embryos by the sperm-mediated gene transfer method. As integrating vectors may lead to insertional mutagenesis and variable transgene expression, and they can undergo silencing, non-viral vectors are preferred. Scaffold/matrix attachment region-based non-viral expression systems (pEPI), that replicate autonomously in mammalian cells, may enable safe and reliable genetic modification of higher eukaryotic cells and organisms. Their results, and the important absence of mosaicism, are an important step forward in animal transgenesis for biomedical applications and might provide a basis for the future development of germ-line gene therapy (113).

Pilling and co-workers in safety assessment studies at GSK, Ware, reported particle-mediated DNA delivery for DNA vaccination against hepatitis B in minipigs, determining toxicity (there were a small number of phagocytosed gold particles) and biodistribution of the pDNA which was present and day 57 and by day 141 had cleared. The minipig is regarded as a good model for humans so their data support the hypothesis that particle-mediated DNA delivery will be safe in human clinical applications (114).

Pigs and rhesus macaques are good models for efforts to improve DNA vaccination immune potency and gene delivery. In electroporation studies of pDNA delivery to target tissues, namely the skin. Hirao et al. in the School of Medicine, University of Pennsylvania, studied the effect of electroporation with high plasmid concentrations resulting in improved gene expression for pGFP delivered by the intradermal/subcutaneous (ID/SQ) route. In a macaque model, they observed higher cellular and humoral responses to an HIV DNA vaccine, which included plasmid-encoded IL12 , with electroporation compared to ID/SQ injection alone. The induced responses were TH1 mediated. Therefore, skin electroporation may be important as an immunization approach in larger animal models (115).

Pigs are also used for xenotransplantation. Pigs are regarded as the next-best source of replacement organs because porcine organs are similar in size to their human counterparts. However, the human immune system recognises pig organs as foreign. Recently, these problems have been addressed by the genetic modification of pigs to alter the antigens displayed on the cell surface. One of the major barriers to pig-human organ transplants is a particular type of sugar molecule, Gal- $\alpha(1,3)$-Gal, which is added to proteins on the surface of pig cells but not human cells. Attempts have been made to reduce the amount of this sugar by expressing antibodies against it, inhibiting the enzyme $\alpha(1,3)$-galactosyltransferase that is only present in pigs, or using additional enzymes to modify it (116).

\section{SHEEP MODELS}

Lehn and co-workers reported transfection of foetal sheep airways in utero using guanidinium-cholesterol cationic lipids (117). Gene therapy, to reduce rejection-mediated damage, holds out some promise as a novel therapeutic strategy in corneal transplantation as the donor cornea can easily be manipulated, ex vivo, prior to transplantation (118). The corneal endothelium is the major target in human corneal graft rejection. As these cells are essentially postmitotic, any such damage cannot be repaired through cell division. The sheep is a useful model in this respect, as ovine endothelial cells are amitotic. In the absence of topical immunosuppression, corneal allografts become spontaneously vascularized and undergo irreversible rejection at 3 weeks postoperatively in a manner that is clinically and histologically similar to human corneal graft rejection and therefore particularly useful (118).

\section{EQUINE MODELS}

The horse is a good model for osteoarthritis as the disease occurs naturally in this species. Osteoarthritis (OA) in horses and in humans is a significant social and economic problem (119).

Adenoviral-mediated gene transfer was used to investigate the therapeutic effects resulting from intra-articular overexpression of the equine interleukin-1 receptor antagonist gene in an established model of equine osteoarthritis that mimics clinical osteoarthritis. In vivo delivery of the equine IL-IRa gene led to elevated intra-articular expression of interleukin-1 receptor antagonist for approximately 28 days, resulting in significant improvement in clinical parameters of pain and disease activity, preservation of articular cartilage, and beneficial effects on the histological parameters of synovial membrane and articular cartilage (120). In horse, an osteochondral fragment was created in one randomly selected intercarpal joint, to produce an experimental OA, and the opposite joint served as the control (Fig. 12). Fourteen days after surgery, they received Ad-EqIL-1Ra viral particles/joint diluted with Gey's balanced salt solution (GBSS) in their joint with a lesion, while the opposite nonfragmented joint received a similar volume of GBSS. Clinical examination of the horses showed that the therapeutic expression of IL-1Ra significantly decreased signs of joint pain as measured by degree of lameness (120).

\section{NON-HUMAN PRIMATE MODELS}

Non-human primate models for preclinical gene vector safety and efficacy trials are performed in a macaque model $(51,52)$, rhesus macaque (Macaca mulatta), in the owl monkey (Aotus trivirgatus), and the common marmoset (Callithrix jacchus). M. mulatta is an important model for human disease research. Affymetrix GeneChip ${ }^{\circledR}$ Rhesus Macaque Genome Array allows simultaneous interrogation of over 47,000 M. mulatta transcripts.

siRNAs can be used together with hematopoietic stem cell transplants stably to modulate gene expression in non-human primates and therefore potentially to treat blood diseases e.g. HIV-1 (121). The HIV-1 coreceptor, (C-C motif) chemokine receptor 5 (CCR5), was selected as a model to examine the feasibility of long-term and stable down-regulation of cellular target gene by siRNA. CCR5 is an ideal target because it is essential for infection by most strains of HIV-1 and it is dispensable in normal humans. Down-regulation of CCR5 by siRNA was demonstrated to protect primary human $\mathrm{T}$ lymphocytes in culture from CCR5 tropic HIV-1 infection. Although effective inhibition of HIV-1 infection was observed, cytotoxicities in T lymphocytes correlated with CCR5 siRNA 
a

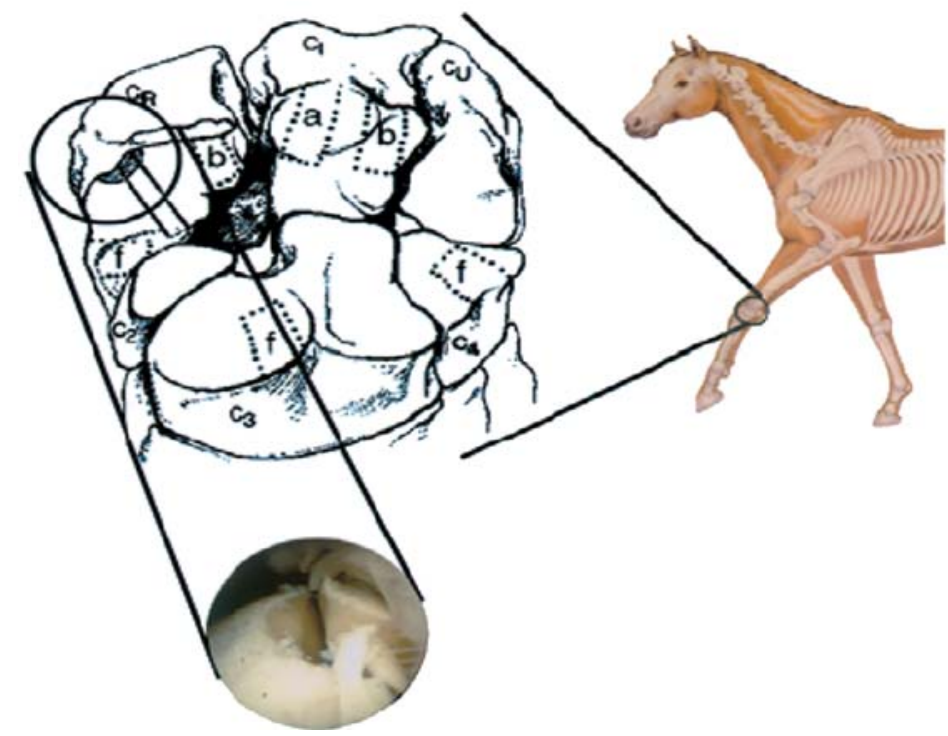

Fig. 12. a Dorsal view of the equine intercarpal joint depicting areas of specific tissue sampling and the osteochondral fragment. b The design of the in vivo OA model (120). Reprinted by permission from Macmillan Publishers Ltd: Gene Therapy (120), copyright (2002).

expression levels. However, by using the weaker $\mathrm{H} 1$ promoter, rather than the U6 promoter to express shRNA reduced toxicities, the potency of the siRNAs was also attenuated (121123). Importantly, apparent adverse effects were not observed from the use of lentiviral-mediated siRNA delivery on hematopoietic stem cell differentiation, $\mathrm{T}$ cell levels, subset phenotypes, or by gross measures of lymphocyte activation $(124,125)$.

In efforts to improve DNA vaccine immune potency, electroporation has emerged as a method for pDNA delivery to target tissues. However, few studies have examined the use of this technology to deliver plasmid vaccines to the skin. As detailed above, Hirao et al. reported ${ }^{121}$ the effects of electroporation on DNA vaccine potency and gene delivery using skin as a target tissue in a pig and a macaque model by the intradermal/subcutaneous route.

Working in experimental psychology at the University of Cambridge, Eslamboli et al. are investigating the therapeutic potential of glial cell line-derived neurotrophic factor (GDNF) for Parkinson's disease using rAAVs expressing GDNF as a delivery system in the common marmoset. Efficacy is likely to depend on sustained delivery of a therapeutic amount to target areas without affecting the function of the normal dopamine (DA) neurons. Unilateral intrastriatal injection of rAAV resulting in the expression of low levels of GDNF (0.04 ng/mg of tissue) provided approximately $85 \%$ protection of the nigral DA neurons and their projections to the striatum in the 6-OHDA-lesioned hemisphere. When delivered continuously, a low level of GDNF in the striatum (approximately threefold above baseline) is sufficient to provide optimal functional outcome (126).

The owl monkey (A. trivirgatus) has served as the standard non-human primate model of herpes simplex virus1 (HSV-1) infection because it is highly susceptible to HSV-1 encephalitis. Owl monkeys, however, are expensive, difficult to obtain, and difficult to maintain in captivity, thus greatly hampering the efficiency of preclinical gene therapy trials for brain tumours using HSV-1-based vectors. Workers at Harvard Medical School have therefore recently compared the susceptibility of the common marmoset (C. jacchus) with the owl monkey in a model of intracerebral inoculation of wildtype HSV-1 F-strain. The common marmosets consistently succumbed earlier to viral encephalitis than the owl monkeys. The common marmoset is at least as susceptible to intracerebral HSV-infection as the owl monkey and can therefore serve as a valid and reliable experimental model for the important preclinical safety tests of HSV-based therapeutic viral vector constructs in the brain (127). The safe and efficient use of HSV-based vectors to deliver genes of potentially therapeutic benefit to the CNS requires their effective disablement by the inactivation of viral genes required for lytic growth. Viruses lacking functional genes for ICP27 (which is required for growth in all cell types) and ICP34.5 (which is required for growth in non-dividing cell types) can efficiently deliver a marker gene to both rodent and primate CNS with relatively minimal damage. Such viruses paradoxically deliver genes at much higher efficiency than the less disabled single mutant lacking ICP34.5 alone and produce less damage in vivo. ICP27- and ICP34.5-viruses thus offer a platform for the development of vectors which are sufficiently safe for ultimate use in human gene therapy (128).

Before autoimmune diseases (e.g. rheumatoid arthritis and multiple sclerosis) in humans can be treated with gene therapy, the safety and efficacy of the used vectors must be tested in valid experimental models. Monkeys, e.g. the rhesus macaque or the common marmoset, are such models that are now starting to be investigated (129). Non-human primate models are useful to evaluate the safety and efficacy of therapeutic gene therapy, before the initiation of clinical trials in humans. With this aim, Hibino et al. have focussed on a 
small New World monkey, the common marmoset, as a target preclinical model and its susceptibility to transduction by retroviral vectors. Marmosets underwent transplantation with autologous peripheral blood progenitor cells (PBPCs) transduced with a retroviral vector carrying the multidrug resistance 1 gene (MDR1). They demonstrated that this small non-human primate is a useful model for the evaluation of gene transfer methods targeting hematopoietic stem cells (130).

Development of therapeutic agents against emerging infectious diseases, e.g. severe acute respiratory syndrome (SARS) viral infections, with siRNA exemplifies this powerful new technology. Potent siRNA inhibitors of SARS coronavirus (SCV) in vitro were evaluated for efficacy and safety in a rhesus macaque ( $M$. mulatta) SARS model using clinically viable delivery while comparing three dosing regimens which consistently showed siRNA-mediated antiSARS efficacy by either prophylactic or therapeutic regimens. The $10-40 \mathrm{mg} / \mathrm{kg}$ accumulated dosages of siRNA did not show any sign of siRNA-induced toxicity. These results suggest that a clinical investigation is warranted and illustrate the prospects for siRNA to enable a massive reduction in development time for new targeted therapeutic agents (131).

Huntington's disease (HD) is a neurological disorder caused by a genetic mutation in the IT15 gene with characteristic progressive cell death in the striatum and cortex, and accompanying declines in cognitive, motor, and psychiatric functions. Animal models of HD provide insight into disease pathology and the outcomes of therapeutic strategies. The discovery, in 1993, of the huntingtin mutation led to the creation of newer models that incorporate a similar genetic defect. These models, which include transgenic and knock-in rodents, are more representative of the HD progression and pathology. An even more recent model that uses a viral vector to encode the gene mutation in specific areas of the brain may be useful in non-human primates, as it is difficult to produce genetic models in these species (132).

\section{APPROPRIATE SELECTION OF ANIMAL MODELS FOR POLYNUCLEIC ACID DELIVERY STUDIES}

In our critical assessment as to which animal models are more appropriate for certain types of polynucleic acid delivery studies, and specifically with regard to "making the appropriate selection", it still does depend upon the disease state under investigation. Whilst it is sure that the vast majority of the animal models used in the laboratory are mice and rats because of well rehearsed arguments: they are small, easy to work with, inexpensive to keep, their generation time is short and they have large litters that can allow controlled breeding programmes, however, in part because of their short lifespan, murine models may fail to reproduce authentically the human diseases process. Therefore, longitudinal studies still need to be performed in large animal models. Dog, cat, sheep and, in general, large animal models have a longer lifespan, their physiological parameters, e.g. their immune system, and their size make them more similar to humans than the murine models. This does not address the question of ethics, and certainly not of cost. The use of larger animal models allows the disease states to be modelled more accurately than rodent models, some of these diseases are even naturally occurring e.g. gene therapy has been evaluated in the brains of cats affected with $\alpha$-mannosidosis (AMD) and the $R P E 65^{-1-}$ dog suffers from early and severe visual impairment, similar to that seen in human Leber congenital amaurosis (LCA). The pig can be used both for the prevention of (porcine) foot-and-mouth disease and in studying human heart disease. Horses naturally develop arthritis. Even choosing to move to fish as an initial model is, quite rightly, covered by the same ethical issues as murine models. So we are not advocating zebrafish as an insignificant model, rather we are highlighting that some fish models may enable useful biological data to be collected in certain research areas, with regard to skin pigmentation, deafness, and for cancer studies, and especially we stress that fish are relevant for the ease of production of 200-600 embryos and then looking in vivo with single cell resolution. The cellular and genetic basis of disease (phenotypes at high resolution) can be routinely studied in zebrafish and medaka. We are keenly aware of the importance of refinement (in the experiment), reduction (in the total number of animals used), and replacement (of animals with cells lines or computer modelling) (the $3 \mathrm{Rs}$ ). We are not aware of any published examples that did not translate from one model to another. Animals are useful models for studying a treatment hypothesis of a specific disease, but we always need to verify that hypothesis in human clinical trials.

Humans and rodents, or indeed most animals (including rabbits, dogs, cats, monkeys, apes) have roughly the same number of nucleotides in their genomes, three billion bp, so a similar number of genes. Whilst the number of human genes without a clear (mouse) counterpart, and vice versa, may not be significantly larger than $1 \%$ of the total, nevertheless, these novel genes may play an important role in determining species-specific traits and functions (http://www.ornl.gov/sci/ techresources/human_genome/faq/compgen.shtml). In the context of known inherited human diseases: a single nucleotide change can lead to the inheritance of sickle cell disease, cystic fibrosis, or breast cancer. A single nucleotide change can alter protein function deleteriously and major morphological differences can likewise occur. The same change, in the same gene, but in different positions in the coding sequence might do no harm at all. So, although we are very similar to all other mammals, it is the subtle changes in the 30,000 genes, alternative splicing and post-translational modification (differing between species) that make (in part, not forgetting the environment) for complexity.

\section{ETHICAL CONSIDERATIONS USING POLYNUCLEIC ACID THERAPY}

In the very near future, as the techniques of gene therapy and RNAi become simpler and more accessible, society will need to deal with some complex ethical questions. One such question is related to the possibility of genetically altering human eggs or sperm, the reproductive cells that pass genes on to future generations. Another question is related to the potential for enhancing human capabilities, e.g. genetic intervention to improve memory and intelligence. Although both germ-line gene therapy and genetic enhancement have the potential to produce benefits, possible problems with these procedures are correctly of widespread concern. Germ- 
line gene therapy would forever change the genetic makeup of an individual's descendants. Thus, the human gene pool would be permanently affected. Although these changes would presumably be for the better, an error in technology or judgment could have far-reaching consequences. In the case of genetic enhancement, there is concern that such manipulation could become a luxury available only to the rich and powerful. Some also fear that widespread use of this technology could lead to new definitions of "normal" that would exclude individuals who are, for example, of merely average intelligence. Researchers on the Human Genome Project (HGP) recognized that the information gained would have profound implications for individuals, families, and society. The Ethical, Legal, and Social Implications (ELSI) Research Program was established in 1990 as part of the HGP to address these issues. The ELSI Research Program promotes basic and applied research on the implications of genetic and genomic research for individuals, families, and communities (http://www.ornl.gov/sci/techresources/Human Genome/medicine/genetherapy.shtml).

\section{CONCLUSIONS}

Most diseases that are currently viewed as candidates for gene therapy are caused by mutations resulting in the absence (malfunctioning) of a particular protein, e.g. enzyme deficiencies, missing ion channels, or are the result of dysregulation/failure of controlled cell growth, i.e. cancer. In most gene therapy studies, a "corrected" gene is inserted into the genome to replace an "abnormal" disease-causing gene. The genetic approach can also be used to reveal new targets for therapies, as in our recent work on inflammation in CD1 strain mice uncovering a potential new target for anti-asthma research (133). To understand fully and to treat genetic diseases in patients, the use of authentic animal models is required in studies that for ethical reasons and lack of (human) volunteers are not possible. The species of animals that are used in gene therapy studies are widespread as highlighted in our review. They have been selected on the basis that the animals had similar clinical signs to affected humans, demonstrating similar genetic mechanisms underlying the diseases in both species, or on their size (weight) and metabolism. Thus, there are many excellent animal models available to investigate target diseases using the new technologies of gene therapy and RNAi.

\section{ACKNOWLEDGEMENTS}

We are grateful to The Erasmus Studentship Travel Scheme for partial financial support (to C.Z.). This review was written under the Erasmus Programme from the University "La Sapienza", Rome, at the University of Bath.

\section{REFERENCES}

1. I. S. Blagbrough, A. J. Geall, and A. P. Neal. Polyamines and novel polyamine conjugates interact with DNA in ways that can be exploited in non-viral gene therapy. Biochem. Soc. Trans. 31:397-406 (2003). doi:10.1042/BST0310397.
2. G. Roman, R. Pálffy, J. Hodosy, J. Lukács, J. Turňa, and P. Celec. Vectors and delivery systems in gene therapy. Med. Sci. Monitor. 11:110-121 (2005).

3. A. Ragusa, I. García, and S. Penadés. Nanoparticles as nonviral gene delivery vectors. IEEE. Trans. Nanobiosci. 6:319-330 (2007). doi:10.1109/TNB.2007.908996.

4. I. S. Blagbrough, and H. M. Ghonaim. Polyamines and their conjugates for gene and siRNA delivery. In: Biological aspects of biogenic amines, polyamines and conjugates. (Ed. G. Dandrifosse), Research Signpost, India, 26 pp. (2008) in press.

5. D. M. Dykxhoorn, and J. Lieberman. The silent revolution: RNA interference as basic biology, research tool, and therapeutic. Annu. Rev. Med. 56:401-423 (2005). doi:10.1146/ annurev.med.56.082103.104606.

6. S. D. Pattinson. Regulating germ-line gene therapy to avoid sliding down the slippery slope. Med. Law Int. 4:213-222 (2000).

7. W. Hecht, and V. Dzapo. The pig mitochondrial genome. Ibex. JME. 3:19-20 (1995).

8. J. U. Pontius, J. C. Mullikin, and D. R. Smith et al. Initial sequence and comparative analysis of the cat genome. Genome Res. 17:1675-1689 (2007). doi:10.1101/gr.6380007.

9. R. Korstanje, P. C. M. O’Brien, F. Yang, W. Rens, A. A. Bosma, H. A. van Lith, L. F. M. van Zutphen, and M. A. FergusonSmith. Complete homology maps of the rabbit (Oryctolagus cuniculus) and human by reciprocal chromosome painting. Cytogenet. Cell Genet. 86:317-322 (1999). doi:10.1159/ 000015325 .

10. J. M. Wilson. Animal models of human disease for gene therapy. J. Clin. Invest. 97:1138-1141 (1996). doi:10.1172/ JCI118527.

11. M. Casal, and M. Haskins. Large animal models and gene therapy. Eur. J. Human Genetics. 14:266-272 (2006). doi:10.1038/sj.ejhg.5201535.

12. K. K. Jain. Commercial Potential of RNAi. Mol. BioSyst. 2:523526 (2006). doi:10.1039/b611485g.

13. Y. Chen, G. Cheng, and R. I. Mahato. RNAi for Treating Hepatitis B Viral Infection. Pharm. Res. 25:72-86 (2008). doi:10.1007/s11095-007-9504-0.

14. T. Nguyen, E. M. Menocal, J. Harborth, and J. H. Fruehauf. RNAi therapeutics: An update on delivery. Curr. Opin. Molec. Therap. 10:158-167 (2008).

15. A. R. De Fougerolles. Delivery vehicles for small interfering RNA in vivo. Human Gene Ther. 19:125-132 (2008). doi:10.1089/hum.2008.928.

16. Handbook of Anticancer Pharmacokinetics and Pharmacodynamics. Eds. W. Figg and H. McLeod, Humana Press, 623 pp (2004).

17. J. M. Lanao, and M. A. Fraile. Drug tissue distribution: study methods and therapeutic implications. Curr. Pharm. Des. 11:3829-3845 (2005). doi:10.2174/138161205774580679.

18. M. Nishikawa, Y. Takakura, and M. Hashida. Pharmacokinetic considerations regarding non-viral cancer gene therapy. Cancer Sci. 99:856-862 (2008). doi:10.1111/j.1349-7006.2008.00774.x.

19. J. C. Schmitz, A. Pandyra, J. Koropatnick, and R. W. Berg. Pharmacokinetics of Nucleic-Acid-Based Therapeutics. In S. C. Gad (ed), Handbook of Pharmaceutical Biotechnology, John Wiley and Sons Inc, 2007, pp 1061-1086.

20. L. M. Houdebine. Use of transgenic animals to improve human health and animal production. Reprod. Dom. Anim. 40:269-281 (2005). doi:10.1111/j.1439-0531.2005.00596.x.

21. N. E. Sharpless, and R. A. DePinho. Model organisms: The mighty mouse: genetically engineered mouse models in cancer drug development. Nature Reviews Drug Discovery. 5:741-754 (2006). doi:10.1038/nrd2110.

22. M. Singh, and L. Johnson. Using genetically engineered mouse models of cancer to aid drug development: an industry perspective. Clin. Cancer Res. 12:5312-5328 (2006). doi:10.1158/1078-0432.CCR-06-0437.

23. R. Galletti, S. Masciarelli, C. Conti, G. Matusali, L. Di Renzo, S. Meschini, G. Arancia, C. Mancini, and E. Mattia. Inhibition of Epstein Barr Virus LMP1 gene expression in B lymphocytes by antisense oligonucleotides: uptake and efficacy of lipid-based and receptor-mediated delivery systems. Antiviral Res. 74:102110 (2007). doi:10.1016/j.antiviral.2006.09.001.

24. A. J. Geall, M. A. W. Eaton, T. Baker, C. Catterall, and I. S. Blagbrough. The regiochemical distribution of positive charges 
along cholesterol polyamine carbamates plays significant roles in modulating DNA binding affinity and lipofection. FEBS Lett. 459:337-342 (1999). doi:10.1016/S0014-5793(99)01262-4.

25. O. A. A. Ahmed, N. Adjimatera, C. Pourzand, and I. S. Blagbrough. $N^{4}, N^{9}$-Dioleoyl spermine is a novel non-viral lipopolyamine vector for plasmid DNA formulation. Pharm. Res. 22:972-980 (2005). doi:10.1007/s11095-005-4592-1.

26. D. McLaggan, N. Adjimatera, K. Sepčić, M. Jaspars, D. J. MacEwan, I. S. Blagbrough, and R. H. Scott. Pore forming polyalkylpyridinium salts from marine sponges versus synthetic lipofection systems: Distinct tools for intracellular delivery of cDNA and siRNA. BMC Biotechnol. 6:6 (2006)(12 pp January). doi:10.1186/1472-6750-6-6.

27. O. A. A. Ahmed, C. Pourzand, and I. S. Blagbrough. Varying the unsaturation in $N^{4}, N^{9}$-dioctadecanoyl spermines: nonviral lipopolyamine vectors for more efficient plasmid DNA formulation. Pharm. Res. 23:31-40 (2006). doi:10.1007/s11095005-8717-3.

28. N. Adjimatera, T. Kral, M. Hof, and I. S. Blagbrough. Lipopolyamine-mediated single nanoparticle formation of calf thymus DNA analyzed by fluorescence correlation spectroscopy. Pharm. Res. 23:1564-1573 (2006). doi:10.1007/s11095-006-0278-6.

29. N. Adjimatera, A. P. Neal, and I. S. Blagbrough. Fluorescence techniques in non-viral gene therapy. In M. Hof, R. Hutterer, and V. Fidler (eds.), Fluorescence Spectroscopy in Biology Advanced Methods and their Applications to Membranes, Proteins, DNA, and Cells, Fluorescence Methods and Applications (Series Ed OS Wolfbeis) vol 3, Springer-Verlag, Berlin, 2005, pp. 201-228.

30. N. Adjimatera, A. Benda, I. S. Blagbrough, M. Langner, M. Hof, and T. Kral. Fluorescence correlation spectroscopic studies of a single lipopolyamine-DNA nanoparticle. In M. BerberanSantos (ed.), Fluorescence of Supermolecules, Polymers, and Nanosystems, Fluorescence (Series Ed OS Wolfbeis) vol 4, Springer-Verlag, Berlin, 2008, pp. 381-413.

31. S. Elworthy, J. A. Lister, T. J. Carney, D. W. Raible, and R. N. Kelsh. Transcriptional regulation of mitfa accounts for the sox10 requirement in zebrafish melanophore development. Development. 130:2809-2818 (2003). doi:10.1242/dev.00461.

32. R. N. Kelsh. Sorting out Sox10 functions in neural crest development. Bioessays. 28:788-98 (2006). doi:10.1002/ bies.20445.

33. B. N. Kennedy, Y. Alvarez, S. E. Brockerhoff, G.W. Stearns, B. Sapetto-Rebow, M. R. Taylor, and J. B. Hurley. Identification of a zebrafish cone photoreceptor-specific promoter and genetic rescue of achromatopsia in the nof mutant. Invest. Ophthalmol. Vis. Sci. 48:522-529 (2007). doi:10.1167/iovs.06-0975.

34. M. Furutani-Seiki, T. Sasado, C. Morinaga, H. Suwa, K. Niwa, H. Yoda, T. Deguchi, Y. Hirose, and A. Yasuoka. A systematic genome-wide screen for mutations affecting organogenesis in Medaka, Oryzias latipes. Mech. Dev. 121:647-658 (2004). doi:10.1016/j.mod.2004.04.016.

35. T. Watanabe, S. Asaka, D. Kitagawa, K. Saito, R. Kurashige, T. Sasado, C. Morinaga, H. Suwa, and K. Niwa. Mutations affecting liver development and function in Medaka, Oryzias latipes, screened by multiple criteria. Mech. Dev. 121:791-802 (2004). doi:10.1016/j.mod.2004.04.004.

36. A. Koga, A. Shimada, T. Kuroki, H. Hori, J. Kusumi, Y. KyonoHamaguchi, and S. Hamaguchi. The Tol1 transposable element of the medaka fish moves in human and mouse cells. J. Hum. Genet. 52:628-635 (2007). doi:10.1007/s10038-007-0161-2.

37. N. Jimenez, J. Coll, F. J. Salguero, and C. Tafalla. Co-injection of interleukin 8 with the glycoprotein gene from viral haemorrhagic septicemia virus (VHSV) modulates the cytokine response in rainbow trout (Oncorhynchus mykiss). Vaccine. 24:5615-5626 (2006). doi:10.1016/j.vaccine.2006.04.061.

38. Q. L. Lu, C. J. Mann, F. Lou, G. Bou-Gharios, G. E. Morris, S. A. Xue, S. Fletcher, T. A. Partridge, and S. D. Wilton. Functional amounts of dystrophin produced by skipping the mutated exon in the mdx dystrophic mouse. Nat. Med. 9:10091014 (2003). doi:10.1038/nm897.

39. L. Zhou, C. R. Dey, S. E. Wert, M. D. DuVall, R. A. Frizzell, and J. A. Whitsett. Correction of lethal intestinal defect in a mouse model of cystic fibrosis by human CFTR. Science. 266:1705-1708 (1994). doi:10.1126/science.7527588.
40. I. Carvalho-Oliverira, B. J. Scholte, and D. Penque. What have we learned from mouse models for cystic fibrosis? Expert Rev. Mol. Diagn. 7:407-417 (2007). doi:10.1586/14737159.7.4.407.

41. F. Takeshita, and T. Ochiva. Therapeutic potential of RNA interference against cancer. Cancer Sci. 97:689-696 (2006). doi:10.1111/j.1349-7006.2006.00234.x.

42. D. A. Fluri, M. D. Baba, and M. Fussenegger. Adenoassociated viral vectors engineered for macrolide-adjustable transgene expression in mammalian cells and mice. $B M C$ Biotechnol. 7:75 (2007). doi:10.1186/1472-6750-7-75.

43. M. A. McAnuff, G. R. Retting, and K. G. Rice. Potency of siRNA versus shRNA mediated knockdown in vivo. J. Pharm. Sci. 96:2922-2930 (2007). doi:10.1002/jps.20968.

44. F. Siller-Lopez, A. Sandoval, S. Salgado, A. Salazar, M. Bueno, J. Garcia, J. Vera, J. Galvez, I. Hernandez, M. Ramos, E. Aguilar-Cordova, and J. Armendariz-Borunda. Treatment with human metalloproteinase- 8 gene delivery ameliorates experimental rat liver cirrhosis. Gastroenterology. 126:1122-1133 (2004). doi:10.1053/j.gastro.2003.12.045.

45. S. Salgado, J. Garcia, J. Vera, F. Siller, M. Bueno, A. Miranda, A. Segura, G. Grijalva, J. Segura, H. Orozco, R. HernandezPando, M. Fafutis, L. K. Aguilar, E. Aguilar-Cordova, and J. Armendariz-Borunda. Liver cirrhosis is reverted by urokinasetype plasminogen activator gene therapy. Mol. Ther. 2:545-551 (2000). doi:10.1006/mthe.2000.0210.

46. Y. Iimuro, and D. A. Brenner. Matrix metalloproteinase gene delivery for liver fibrosis. Pharm. Res. 25:249-258 (2008). doi:10.1007/s11095-007-9311-7.

47. M. L. Batten, Y. Imanishi, D. C. Tu, T. Doan, L. Zhu et al. Pharmacological and rAAV gene therapy rescue of visual functions in a blind mouse model of Leber congenital amaurosis. PLoS Med. 2:333 (2005). doi:10.1371/journal.pmed.0020333.

48. C. S. Chen, Y. Jounaidi, T. Su, and D. J. Waxman. Enhancement of intratumoral cyclophosphamide pharmacokinetics and antitumor activity in a P450 2B11-based cancer gene therapy model. Cancer Gene Ther. 14:935-944 (2007). doi:10.1038/sj. cgt.7701092.

49. Z. Q. Huang, M. K. Raychowdhury, and D. J. Waxman. Impact of liver P450 reductase suppression on cyclophosphamide activation, pharmacokinetics and antitumoral activity in a cytochrome P450-based cancer gene therapy model. Cancer Gene Ther. 7:1034-1042 (2000). doi:10.1038/sj.cgt.7700200.

50. M. Harada-Shiba, K. Yamauchi, A. Harada, I. Takamisawa, K. Shimokado, and K. Kataoka. Polyion complex micelles as vectors in gene therapy - pharmacokinetics and in vivo gene transfer. Gene Ther. 9:407-414 (2002). doi:10.1038/sj.gt.3301665.

51. S. E. Parker, H. L. Vahlsing, D. Lew, T. Martin, B. Hall, D. Kornbrust, and J. Norman. Cancer gene therapy using plasmid DNA: Pharmacokinetics and safety evaluation of an IL-2 plasmid DNA expression vector in rodents and non-human primates. Biopharm-The Appl. Technol. Biopharm. Dev. 12:18-24 (1999).

52. J. A. Norman, S. Parker, D. Lew, M. Manthorpe, and M. Marquet. Preclinical pharmacokinetics, manufacturing, and safety studies supporting a multicenter cancer gene-therapy trial. Human Gene Ther. 6:549-550 (1995). doi:10.1089/hum.1995.6.5-549.

53. K. Kunath, A. von Harpe, D. Fischer, H. Petersen, U. Bickel, K. Voigt, and T. Kissel. Low-molecular-weight polyethylenimine as a non-viral vector for DNA delivery: comparison of physicochemical properties, transfection efficiency and in vivo distribution with high-molecular-weight polyethylenimine. $J$. Control. Release. 89:113-25 (2003). doi:10.1016/S0168-3659(03) 00076-2.

54. A. J. Geall, and I. S. Blagbrough. Rapid and sensitive ethidium bromide fluorescence quenching assay of polyamine conjugateDNA interactions for the analysis of lipoplex formation in gene therapy. J. Pharm. Biomed. Anal. 22:849-859 (2000). doi:10.1016/S0731-7085(00)00250-8.

55. W. M. Pardridge. Intravenous, non-viral RNAi gene therapy of brain cancer. Expert. Opin. Biol. Ther. 4:1103-1113 (2004) doi:10.1517/14712598.4.7.1103.

56. H. Mok, D. J. Palmer, P. Ng, and M. A. Barry. Evaluation of polyethylene glycol modification of first-generation and helperdependent adenoviral vectors to reduce innate immune responses. Mol. Ther. 11:66-79 (2005). doi:10.1016/j. ymthe.2004.09.015. 
57. S. E. Hofherr, H. Mok, F. C. Gushiken, J. A. Lopez, and M. A. Barry. Human Gene Therapy. 18:837-848 (2007). doi:10.1089/ hum.2007.0051.

58. T. Kuboki, T. Nakanishi, M. Kanyama, W. Sonoyama, T. Fujisawa, K. Kobayashi, T. Ikeda, T. Kubo, A. Yamashita, and M. Takigawa. Direct adenovirus-mediated gene delivery to the temporomandibular joint in guinea-pigs. Arch. Oral. Biol. 44:701-709 (1999). doi:10.1016/S0003-9969(99)00069-2.

59. W. Chen, M. Liu, Y. Liao, W. Yan, X. Wei, J. Chen, L. Fei, Y. Liu, X. Zuo, F. Yang, Y. Lu, and Z. Zheng. Adenovirusmediated RNA interference against foot-and-mouth disease virus infection both in vitro and in vivo. J. Virol. 80:3559-3566 (2006). doi:10.1128/JVI.80.7.3559-3566.2006.

60. N. Matsuoka, K. Nozaki, Y. Takagi, M. Nishimura, J. Hayashi, S. Miyatake, and N. Hashimoto. Adenovirus-mediated gene transfer of fibroblast growth factor-2 increases BrdU-positive cells after forebrain ischemia in gerbils. Stroke. 34:1519-1525 (2003). doi:10.1161/01.STR.0000070840.56414.3B.

61. N. Hakuba, K. watabe, J. Hyodo, T. Ohashi, Y. Eto, M. Taniguchi, L. Yang, J. Tanaka, R. Hata, and K. Gyo. Adenovirus-mediated overexpression of a gene prevents hearing loss and progressive inner hair cell loss after transient cochlear ischemia in gerbils. Gene Ther. 10:426-433 (2003). doi:10.1038/sj.gt.3301917.

62. T. Nomoto, T. Okada, K. Shimazaki, H. Mizukami, T. Matsushita, Y. Hanazono, A. Kume, K. Kastura, Y. Katayama, and K. Ozawa. Distinct patterns of gene transfer to gerbil hippocampus with recombinant adeno-associated virus type 2 and 5. Neurosci. Lett. 340:153-157 (2003). doi:10.1016/S03043940(03)00095-8.

63. J. Mimur, S. Muramatsu, Y. Hakamada, K. Mori, J. Kikuchi, M. Urabe, S. Madoiwa, K. Ozawa, and Y. Sakata. Recombinant adeno-associated virus vector-transduced vascular endothelial cells express the thrombomodulin transgene under the regulation of enhanced plasminogen activator inhibitor-1 promoter Gene Ther. 8:1690-1697 (2001). doi:10.1038/sj.gt.3301579.

64. M. Yamanda, Y. Ikeda, M. Yamo, K. Yoshimura, S. Nishino, H. Aoyama, L. Wang, H. Aoki, and M. Matsuzaki. Inhibition of protein phosphatase 1 by inhibitor- 2 gene delivery ameliorates heart failure progression in genetic cardiomyopathy. FASEB $J$. 20:1197-1199 (2006). doi:10.1096/fj.05-5299fje.

65. J. Li, D. Dressman, Y. P. Tsao, A. Sakamoto, E. P. Hoffman, and X. Xiao. rAAV vector-mediated sarcogylcan gene transfer in a hamster model for limb girdle muscular dystrophy. Gene Ther. 6:74-82 (1999). doi:10.1038/sj.gt.3300830.

66. R. G. Webster, E. F. Fynan, J. C. Santoro, and H. Robinson. Protection of ferrets against influenza challenge with a DNA vaccine to the haemagglutinin. Vaccine. 12:1495-1498 (1994). doi:10.1016/0264-410X(94)90071-X.

67. X. Liu, M. Luo, C. Guo, Z. Yan, Y. Wang, and J. F. Engelhardt Comparative biology of rAAV transduction in ferret, pig and human airway epithelia. Gene Ther. 14:1543-1548 (2007). doi:10.1038/sj.gt.3303014.

68. J. R. Chowdhury, M. Grossman, S. Gupta, N. R. Chowdhury, J. R. Baker, and J. M. Wilson. Long-term improvement of hypercholesterolemia after ex vivo gene therapy in LDLRdeficient rabbits. Science. 254:1802-1805 (1991). doi:10.1126/ science. 1722351.

69. D. Logeart, S. N. Hatem, M. Heimburger, A. Le Roux, J. B. Michel, and J. J. Mercadier. How to optimize in vivo gene transfer to cardiac myocites: mechanical or pharmacological procedures? Hum. Gene Ther. 12:1601-1610 (2001). doi:10.1089/10430340152528101.

70. D. M. Zhao, H. B. Wang, J. F. Yang, S. Q. Wu, J. L. Liu, F. Y. Xu, L. P. Qiuand, and J. L. Cai. Effects of vascular endothelial growth factor 165 gene transfection on bone defects and its mRNA expression in rabbits. Chin. Med. J. 120:1187-1191 (2007).

71. N. G. Abraham, A. Asija, G. Drummond, and S. Peterson. Heme oxygenase-1 gene therapy: recent advances and therapeutic applications. Curr. Gene Ther. 7:89-108 (2007). doi:10.2174/156652307780363134.

72. C. H. Vite, J. C. McGowan, S. N. Niogi, M. A. Passini, K. J. Drobatz, M. E. Haskins, and J. H. Wolfe. Effective gene therapy for an inherited CNS disease in a large animal model. Ann. Neurol. 57:355-364 (2005). doi:10.1002/ana.20392.
73. N. M. Ellinwood, C. H. Vite, and M. E. Haskins. Gene therapy for lysosomal storage diseases: the lessons and promise of animal models. J. Gene Med. 6:481-506 (2004). doi:10.1002/ jgm.581.

74. D. J. WatsonJ. H. Wolfe. Lentiviral vectors for gene transfer to the central nervous system: applications in lysosomal storage disease animal models. In C. MachidaC. Machida (ed)., Viral vectors for gene therapy: methods and protocols, Humana Press, Totowa, NJ, 2002, pp. 383-403.

75. J. H. Wolfe, M. S. Sands, N. Harel, M. A. Weil, M. K. Parente, A. C. Polesky, J. J. Reilly, C. Hasson, S. Weimelt, and M. E. Haskins. Gene transfer of low levels of beta-glucuronidase corrects hepatic lysosomal storage in a large animal model of mucopolysaccharidosis VII. Mol. Ther. 2:552-561 (2000). doi:10.1006/mthe.2000.0202.

76. D. Davis, J. Ulatowski, S. Eleff, M. Izuta, S. Mori, D. Shungu, and P. C. van Zijl. Rapid monitoring of changes in water diffusion coefficients during reversible ischemia in cat and rat brain. Magn. Reson. Med. 231:454-460 (1994). doi:10.1002/ mrm.1910310416.

77. M. Podell, M. Hadjiconstantinou, M. A. Smith, and N. H. Neff. Proton magnetic resonance imaging and spectroscopy identify metabolic changes in the striatum in the MPTP feline model of parkinsonism. Exp. Neurol. 170:159-166 (2003). doi:10.1016/ S0014-4886(02)00015-8.

78. C. H. Vite, J. C. McGowan, K. G. Braund, K. J. Drobatz, J. D. Glickson, J. H. Wolfe, and M. E. Haskins. Histopathology, electrodiagnostic testing, and magnetic resonance imaging show significant peripheral and central nervous system myelin abnormalities in the cat model of alpha-mannosidosis. $J$. Neuropathol. Exp. Neurol. 60:817-828 (2001).

79. R. M. Taylor, and J. H. Wolfe. Decreased lysosomal storage in the adult MPS VII mouse brain in the vicinity of grafts of retroviral vector-corrected fibroblasts secreting high levels of beta-glucuronidase. Nat. Med. 3:771-774 (1997). doi:10.1038/ nm0797-771.

80. E. Y. Snyder, and J. H. Wolfe. Central nervous system cell transplantation: a novel therapy for storage diseases? Curr. Opin. Neurol. 9:126-136 (1996). doi:10.1097/00019052199604000-00013.

81. M. A. Passini, E. B. Lee, G. G. Heuer, and J. H. Wolfe. Distribution of a lysosomal enzyme in the adult brain by axonal transport and by cells of the rostral migratory stream. $J$. Neurosci. 22:6436-6446 (2002).

82. A. K. Hennig, B. Levy, J. M. Ogilvie, C. A. Volgler, N. Galvin, S. Bassnett, and M. S. Sands. Intravitreal gene therapy reduces lysosomal storage in specific areas of the CNS in mucopolysaccharidosis VII mice. J. Neurosci. 23:3302-3307 (2003).

83. S. U. Walkley, M. A. Thrall, K. Dobrenis, M. Huang, P. A. March, D. A. Siegel, and S. Wurzelmann. Bone marrow transplantation corrects the enzyme defect in neurons of the central nervous system in a lysosomal storage disease. Proc. Natl. Acad. Sci. USA. 91:2970-2974 (1994). doi:10.1073/ pnas.91.8.2970.

84. D. A. Wall, D. K. Grange, P. Goulding, M. Daines, A. Luisiri, and S. Kotagal. Bone marrow transplantation for the treatment of alpha-mannosidosis. J. Pediatr. 133:282-285 (1992). doi:10.1016/S0022-3476(98)70237-9.

85. E. A. Ostrander, and E. Giniger. Semper fidelis: What man's best friend can teach us about human biology and disease. Am. J. Hum. Genet. 61:475-480 (1997). doi:10.1086/515522.

86. M. M. Sleeper, B. Fornasari, N. M. Ellinwood, M. A. Weil, J. Melniczek, T. M. O'Malley, C. D. Sammarco, L. Xu, K. P. Ponder, and M. E. Haskins. Gene therapy ameliorates cardiovascular disease in dogs with mucopolysaccharidosis VII. Circulation. 110:815-820 (2004). doi:10.1161/01. CIR.0000138747.82487.4B.

87. M. E. Haskins, R. J. Desnick, N. Di Ferrante, P. F. Jezyk, and D. F. Patterson. Beta-glucoronidase deficiency in a dog: a model of human mucopolysaccharidosis VII. Pediatr. Res. 18:980-984 (1984)

88. J. C. Fyfe, R. L. Kurzhals, M. E. Lassaline, P. S. Henthon, P. R. Alur, P. Wang, J. H. Wolfe, U. Giger, M. E. Haskins, D. F. Patterson, H. Sun, S. Jain, and N. Yuhki. Molecular basis of 
feline beta-glucuronidase deficiency: an animal model of mucopolysaccharidosis VII. Genomics. 58:121-128 (1999). doi:10.1006/geno.1999.5825.

89. P. C. Schultheiss, S. A. Gardner, J. M. Owens, D. A. Wenger, and M. A. Thrall. Mucopolysaccharidosis VII in a cat. Vet. Pathol. 37:502-505 (2000). doi:10.1354/vp.37-5-502.

90. J. Ray, A. Bouvet, C. DeSanto, J. C. Fyfe, D. Xu, J. H. Wolfe, G. D. Aguirre, D. F. Patterson, M. E. Haskins, and P. S. Henthorn. Cloning of the canine beta-glucuronidase cDNA, mutation identification in canine MPS VII, and retroviral vector-mediated correction of MPS VII cells. Genomics. 48:248-253 (1998). doi:10.1006/geno.1997.5189.

91. L. F. Xu, M. E. Haskins, J. R. Melniczek, C. Gao, M. A. Weil, T. M. O'Malley, P. A. O'Donnell, H. Mazrier, N. M. Ellinwood, J. Zweigle, J. H. Wolfe, and K. P. Ponder. Transduction of hepatocytes after neonatal delivery of a Moloney murine leukemia virus based retroviral vector results in long-term expression of beta-glucuronidase in mucopolysaccharidosis VII dogs. Mol. Ther. 5:141-153 (2002). doi:10.1006/mthe. 2002.0527.

92. W. Gu, M. Brooks, J. Catalfamo, J. Ray, and K. Ray. Two distinct mutations cause severe hemophilia B in two unrelated canine pedigrees. Thromb. Haemost. 82:1270-1275 (1999).

93. C. M. Lynch. Gene therapy for hemophilia. Curr. Opin. Mol. Ther. 1:493-499 (1999).

94. W. M. McCormarck Jr., M. P. Seiler, T. K. Bertin, K. Ubhayakar, D. J. Palmer, P. Ng, T. C. Nichols, and B. Lee. Helper-dependent adenoviral gene therapy mediates long-term correction of the clotting defect in the canine hemophilia A model. J. Thromb. Haemost. 4:1218-1225 (2006). doi:10.1111/ j.1538-7836.2006.01901.x.

95. S. R. Bianco, J. Sun, S. P. Fosmire, K. Hance, M. L. Padilla, M. G. Ritt, D. M. Getz, R. C. Duke, S. J. Withrow, S. Lana, D. T. Matthiesen, S. W. Dow, D. Bellgrau, G. R. Cutter, S. C. Helfand, and J. F. Modiano. Enhancing antimelanoma immune responses through apoptosis. Cancer Gene Ther. 10:726-736 (2003). doi:10.1038/sj.cgt.7700625.

96. A. E. Chauvet, P. P. Kesava, C. S. Goh, and B. Badie. Selective intraarterial gene delivery into a canine meningioma. J. Neurosurg. 88:870-873 (1998).

97. S. W. Dow, R. E. Elmslie, A. P. Willson, L. Roche, C. Gorman, and T. A. Potter. In vivo tumor transfection with superantigen plus cytokine genes induces tumor regression and prolongs survival in dogs with malignant melanoma. J. Clin. Invest. 101:2406-2414 (1998). doi:10.1172/JCI510.

98. G. S. Hogge, J. K. Burkholder, J. Culp, M. R. Albertini, R. R. Dubielzing, N. S. Yang, and E. G. MacEwen. Preclinical development of human granulocyte-macrophage colony-stimulating factortransfected melanoma cell vaccine using established canine cell lines and normal dogs. Cancer Gene Ther. 6:26-36 (1999). doi:10.1038/sj.cot.7700015.

99. D. H. Thamm, I. D. Kurzman, E. G. Macewen, R. Feinmehl, T. L. Towell, S. L. Loghofer, C. M. Johnson, F. J. Geoly, and D. T. Stinchcomb. Intralesional lipid complexed cytokine/ superantigen immunogene therapy for spontaneous canine tumours. Cancer Immunol. Immunother. 52:473-480 (2003). doi:10.1007/s00262-003-0387-6.

100. W. Kassouf, G. A. Brown, A. Shetty, J. D. Hazle, R. J. Stafford, C. J. Rosser, C. Stephens, P. T. Tinkey, and L. L. Pisters. An in vivo orthotopic canine model to evaluate distribution of intraprostatic injectate: implications for gene therapy and drug delivery for prostate cancer. Urology. 70:822-825 (2007). doi:10.1016/j.urology.2007.06.637.

101. G. M. Acland, G. D. Aguirre, J. Ray, Q. Zhang, T. S. Aleman, A. V. Cideciyan, S. E. Pearce-Kelling, V. Anand, Y. Zeng, A. M. Maguire, S. G. Jacobson, W. W. Hauswirth, and J. Bennett. Gene therapy restores vision in a canine model of childhood blindness. Nature Genetics. 28:92-95 (2001). doi:10.1038/88327.

102. J. W. Bainbridge, and R. R. Ali. Ocular gene therapy trials due to report this year; keeping an eye on clinical trials in 2008 . Gene Ther. 15:633-634 (2008). doi:10.1038/gt.2008.28.

103. T. Moore. Restoring retinal function in a mouse model of hereditary blindness. PLoS Med. 2:e399 (2005). doi:10.1371/ journal.pmed.0020399.
104. P. A. Harper, P. J. Healy, and J. A. Dennis. Animal model of human disease. Citrullinemia (argininosuccinate synthetase deficiency). Am. J. Pathol. 135:1213-1215 (1989).

105. B. Lee, J. A. Dennis, P. J. Healy, B. Mull, L. Pastore, H. Yu, E. Aguilar-Cordova, W. O'Brien, P. Reeds, and A. L. Beaudet. Hepatocyte gene therapy in a large animal: a neonatal bovine model of citrullinemia. Proc. Natl. Acad. Sci. USA. 96:39813986 (1999). doi:10.1073/pnas.96.7.3981.

106. J. Muhlhauser, M. Jones, I. Yamada, C. Cirielli, P. Lemarchand, T. R. Gloe, B. Bewig, S. Signoretti, R. G. Crystal, and M. C. Capogrossi. Safety and efficacy of in vivo gene transfer into the porcine heart with replication-deficient, recombinant adenovirus vectors. Gene Ther. 3:145-153 (1996).

107. J. K. Donahue, A. W. Heldman, H. Fraser, A. D. McDonald, J. M. Miller, J. J. Rade, T. Eschenhagen, and E. Marban. Focal modification of electrical conduction in the heart by viral gene transfer. Nat. Med. 6:1395-1398 (2000). doi:10.1038/ 82214.

108. B. French, W. Mazur, R. Geske, and R. Bolli. Direct in vivo gene transfer into porcine myocardium using replicationdeficient adenoviral vectors. Circulation. 90:2414-2424 (1994).

109. R. Draghia-Akli and M. L. Fiorotto. A new plasmid-mediated approach to supplement somatotropin production in pigs. $J$. Anim. Sci. 82:E264-269 (2004).

110. J. Cai, F. F. Yi, Y. H. Li, X. C. Yang, J. Song, X. J. Jiang, H. Jiang, G. S. Lin, and W. Wang. Adenoviral gene transfer of HCN4 creates a genetic pacemaker in pigs with complete atrioventricular block. Life Sci. 80:1746-53 (2007). doi:10.1016/ j.lfs.2007.02.006.

111. J. W. Fabre, A. Grehan, M. Whitehorne, G. J. Sawyer, X. Dong, S. Salehi, L. Eckley, X. Zhang, M. Seddon, A. M. Shah, M. Davenport, and M. Rela. Hydrodynamic gene delivery to the pig liver via an isolated segment of the inferior vena cava. Gene Ther. 15:452-62 (2008). doi:10.1038/sj.gt.3303079.

112. P. W. Raake, R. Hinkel, S. Müller, S. Delker, R. Kreuzpointner, C. Kupatt, H. A. Katus, J. A. Kleinschmidt, P. Boekstegers, and O. J. Müller. Cardio-specific long-term gene expression in a porcine model after selective pressure-regulated retroinfusion of adenoassociated viral (AAV) vectors. Gene Ther. 15:12-17 (2008). doi:10.1038/sj.gt.3303035

113. S. Manzini, A. Vargiolu, I. M. Stehle, M. L. Bacci, M. G. Cerrito, R. Giovannoni, A. Zannoni, M. R. Bianco, M. Forni, P. Donini, M. Papa, H. J. Lipps, and M. Lavitrano. Genetically modified pigs produced with a nonviral episomal vector. Proc. Natl. Acad. Sci. USA. 103:17672-17677 (2006). doi:10.1073/ pnas.0604938103.

114. A. M. Pilling, R. M. Harman, S. A. Jones, N. A. McCormack, D. Lavender, and R. Haworth. The assessment of local tolerance, acute toxicity, and DNA biodistribution following particle-mediated delivery of a DNA vaccine to minipigs. Toxicol. Pathol. 30:298-305 (2002). doi:10.1080/ 01926230252929864.

115. L. A. Hirao, L. Wu, A. S. Khan, A. Satishchandran, R. DraghiaAkli, and D. B. Weiner. Intradermal/subcutaneous immunization by electroporation improves plasmid vaccine delivery and potency in pigs and rhesus macaques. Vaccine. 26:440-8 (2008). doi:10.1016/j.vaccine.2007.10.041.

116. C. J. Phelps, C. Koike, T. D. Vaught, J. Boone, K. D. Wells, S. H. Chen, S. Ball, S. M. Specht, I. A. Polejaeva, J. A. Monahan, P. M. Jobst, S. B. Sharma, A. E. Lambom, A. S. Garst, M. Moore, A. J. Demetris, W. A. Rudert, R. Bottino, S. Bertera, M. Trucco, T. E. Starzl, Y. Dai, and D. L. Ayares. Production of alpha 1,3-galactosyltransferase-deficient pigs. Science. 299:411-414 (2003). doi:10.1126/science.1078942.

117. D. Luton, N. Oudrhiri, P. de Laguisie, A. Aissaoui, M. Hauchecorne, S. Julia, J. F. Oury, Y. Aigrain, M. Peuchmaur, J. P. Vigneron, J. M. Lehn, and P. Lehn. Gene transfection into fetal sheep airways in utero using guanidinium-cholesterol cationic lipids. J. Gene Med. 6:328-336 (2004). doi:10.1002/ jgm.559.

118. S. Klebe, P. J. Sykes, D. J. Coster, D. C. Bloom, and K. A. Williams. Gene transfer to ovine corneal endothelium. Clin. Experimental Ophthalmol. 29:316-322 (2001). doi:10.1046/ j.1442-9071.2001.00440.x. 
119. D. D. Frisbie, and C. W. McIlwraith. Evaluation of gene therapy as a treatment for equine traumatic arthritis and osteoarthritis. Clin. Orthop. Relat. Res. 1:S273-S287 (2000). doi:10.1097/00003086-200010001-00037.

120. D. D. Frisbie, S. C. Ghivizzani, P. D. Robbins, C. H. Evans, and C. W. McIlwraith. Treatment of experimental equine osteoarthritis by in vivo delivery of the equine interleukin-1 receptor antagonist gene. Gene Ther. 9:12-20 (2002). doi:10.1038/sj.gt.3301608.

121. D. S. An, R. E. Donahue, M. Kamata, B. Poon, M. Metzger, S. H. Mao, A. Bonifacio, A. E. Krouse, J. L. Darlix, D Baltimore, F. X. Qin, and I. S. Chen. Stable reduction of CCR5 by RNAi through hematopoietic stem cell transplant in nonhuman primates. Proc. Natl. Acad. Sci. USA. 104:13110-13115 (2007). doi:10.1073/pnas.0705474104.

122. J. Anderson, M. J. Li, B. Palmer, L. Remling, S. Li, P. Yam, J. K. Yee, J. Rossi, J. Zaia, and R. Akkina. Safety and efficacy of a lentiviral vector containing three anti-HIV genes-CCR5 ribozyme, tat-rev siRNA, and TAR decoy in SCID-hu mousederived T cells. Mol. Ther. 6:1182-1188 (2007).

123. R. Liu, W. A. Paxton, S. Choe, D. Ceradini, S. R. Martin, R. Horuk, M. E. MacDonald, H. Stuhlmann, R. A. Koup, and N. R. Landau. Homozygous defect in HIV-1 co-receptor accounts for resistance of some multiply-exposed individuals to HIV-1 infection. Cell. 86:367-377 (1996). doi:10.1016/S0092-8674(00)80110-5.

124. X. F. Qin, D. S. An, I. S. Y. Chen, and D. Baltimore. Inhibiting HIV-1 infection in human T cells by lentiviral-mediated delivery of small interfering RNA against CCR5. Proc. Natl. Acad. Sci. USA. 100:183-188 (2003). doi:10.1073/pnas.232688199.

125. T. S. Zimmermann, A. C. Lee, A. Akinc, B. Bramlage, D. Bumcrot, M. N. Fedoruk, J. Harborth, J. A. Heves, L. B. Jeffs, M. John, A. D. Judge, K. Lam, K. McClintock, L. V. Nechev, L. R. Palmer, T. Racie, I. Rohl, S. Seiffert, S. Shanmugam, V. Sood, J. Soutschek, I. Toudjarska, A. J. Wheat, E. Yaworski, W. Zedalis, V. Koteliansky, M. Manoharan, H. P. Vornolocher, and I. MacLachlan. RNAi-mediated gene silencing in non-human primates. Nature. 441:111-114 (2006). doi:10.1038/nature04688.

126. A. Eslamboli, B. Georgievska, R. M. Ridley, H. F. Baker, N. Muzyczka, C. Burger, R. J. Mandel, L. Annett, and D. Kirik.
Continuous low-level glial cell line-derived neurotrophic factor delivery using recombinant adeno-associated viral vectors provides neuroprotection and induces behavioral recovery in a primate model of Parkinson's disease. J. Neurosci. 25:769-777 (2005). doi:10.1523/JNEUROSCI.442104.2005.

127. T. S. Deisboeck, H. Wakimoto, U. Nestler, D. N. Louis, P. K. Sehgal, M. Simon, E. A. Chiocca, and F. H. Hochberg. Development of a novel non-human primate model for preclinical gene vector safety studies. Determining the effects of intracerebral HSV-1 inoculation in the common marmoset: a comparative study. Gene Ther. 10:1225-1233 (2003). doi:10.1038/sj.gt.3302003.

128. M. K. Howard, T. Kershaw, B. Gibb, N. Storey, A. R. MacLean, B. Y. Zeng, B. C. Tel, P. Jenner, S. M. Brown, C. J. Woolf, P. N. Anderson, R. S. Coffin, and D. S. Latchman. High efficiency gene transfer to the central nervous system of rodents and primates using herpes virus vectors lacking functional ICP27 and ICP34.5. Gene Ther. 5:1137-1147 (1998). doi:10.1038/sj. gt.3300700.

129. B. A. t'Hart, M. Vervoordeldonk, J. L. Heeney, and P. P. Tak. Gene therapy in nonhuman primate models of human autoimmune disease. Gene Ther. 10:890-901 (2003). doi:10.1038/sj. gt.3302017.

130. H. Hibino, K. Tani, K. Ikebuchi, M. S. Wu, H. Sugiyama, Y. Nakazaki, T. Tanabe, S. Takahashi, A. Tojo, S. Suzuki, Y. Tanioka, Y. Sugimoto, T. Nakahata, and S. Asano. The common marmoset as a target preclinical primate model for cytokine and gene therapy studies. Blood. 93:2839-2848 (1999).

131. B. J. Li, and Q. Q. Tang. Using siRNA in prophylactic and therapeutic regimens against SARS coronavirus in rhesus macaque. Nat. Med. 11:944-951 (2005).

132. S. Ramaswamy, J. L. McBride, and J. H. Kordower. Animal models of Huntington's disease. ILAR J. 48:356-373 (2007).

133. H. S. M. Farghaly, I. S. Blagbrough, D. A. Medina-Tato, and M. L. Watson. Interleukin 13 increases contractility of murine tracheal smooth muscle by a phosphoinositide 3-kinase p1108 dependent mechanism. Mol. Pharmacol. 73:1530-1537 (2008). doi:10.1124/mol.108.045419. 